\title{
Multistation intercomparison of column-averaged methane from NDACC and TCCON: impact of dynamical variability
}

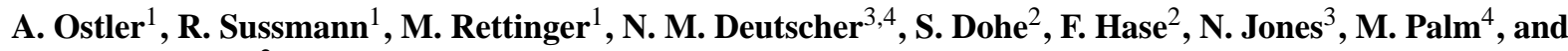 \\ B.-M. Sinnhuber ${ }^{2}$ \\ ${ }^{1}$ Karlsruhe Institute of Technology, IMK-IFU, Garmisch-Partenkirchen, Germany \\ ${ }^{2}$ Karlsruhe Institute of Technology, IMK-ASF, Karlsruhe, Germany \\ ${ }^{3}$ University of Wollongong, New South Wales, Wollongong, Australia \\ ${ }^{4}$ Institute of Environmental Physics, University of Bremen, Bremen, Germany \\ Correspondence to: A. Ostler (andreas.ostler@kit.edu)
}

Received: 10 April 2014 - Published in Atmos. Meas. Tech. Discuss.: 10 July 2014

Revised: 6 October 2014 - Accepted: 21 October 2014 - Published: 3 December 2014

\begin{abstract}
Dry-air column-averaged mole fractions of methane $\left(\mathrm{XCH}_{4}\right)$ retrieved from ground-based solar Fourier transform infrared (FTIR) measurements provide valuable information for satellite validation, evaluation of chemicaltransport models, and source-sink-inversions. In this context, Sussmann et al. (2013) have shown that midinfrared (MIR) soundings from the Network for the Detection of Atmospheric Composition Change (NDACC) can be combined with near-infrared (NIR) soundings from the Total Carbon Column Observing Network (TCCON) without the need to apply an overall intercalibration factor. However, in spite of efforts to reduce a priori impact, some residual seasonal biases were identified, and the reasons behind remained unclear. In extension to this previous work, which was based on multiannual quasi-coincident MIR and NIR measurements from the stations Garmisch $\left(47.48^{\circ} \mathrm{N}, 11.06^{\circ} \mathrm{E}, 743 \mathrm{~m}\right.$ a.s.l.) and Wollongong $\left(34.41^{\circ} \mathrm{S}, 150.88^{\circ} \mathrm{E}, 30 \mathrm{~m}\right.$ a.s.l.), we now investigate upgraded retrievals with longer temporal coverage and include three additional stations (Ny-Ålesund, $78.92^{\circ} \mathrm{N}, 11.93^{\circ} \mathrm{E}, 20 \mathrm{~m}$ a.s.l.; Karlsruhe, $49.08^{\circ} \mathrm{N}, 8.43^{\circ} \mathrm{E}$, $110 \mathrm{~m}$ a.s.1.; Izaña, $28.31^{\circ} \mathrm{N}, 16.45^{\circ} \mathrm{W}, 2.370 \mathrm{~m}$ a.s.l.). Our intercomparison results (except for $\mathrm{Ny}$-Ålesund) confirm that there is no overall bias between MIR and NIR $\mathrm{XCH}_{4}$ retrievals, and all MIR and NIR time series reveal a quasiperiodic seasonal bias for all stations, except for Izaña.

We find that dynamical variability causes MIR-NIR differences of up to $\sim 30 \mathrm{ppb}$ (parts per billion) for $\mathrm{Ny}$ Ålesund, $\sim 20 \mathrm{ppb}$ for Wollongong, $\sim 18 \mathrm{ppb}$ for Garmisch, and $\sim 12 \mathrm{ppb}$ for Karlsruhe. The mechanisms behind this
\end{abstract}

variability are elaborated via two case studies, one dealing with stratospheric subsidence induced by the polar vortex at Ny-Ålesund and the other with a deep stratospheric intrusion event at Garmisch. Smoothing effects caused by the dynamical variability during these events are different for MIR and NIR retrievals depending on the altitude of the perturbation area. MIR retrievals appear to be more realistic in the case of stratospheric subsidence, while NIR retrievals are more accurate in the case of stratosphere-troposphere exchange (STE) in the upper troposphere/lower stratosphere (UTLS) region. About $35 \%$ of the FTIR measurement days at Garmisch are impacted by STE, and about $23 \%$ of the measurement days at $\mathrm{Ny}$-Ålesund are influenced by polar vortex subsidence. The exclusion of data affected by these dynamical situations resulted in improved agreement of MIR and NIR seasonal cycles for Ny-Ålesund and Garmisch.

We found that dynamical variability is a key factor in constraining the accuracy of MIR and NIR seasonal cycles. To mitigate this impact it is necessary to use more realistic a priori profiles that take these dynamical events into account (e.g., via improved models), and/or to improve the FTIR retrievals to achieve a more uniform sensitivity at all altitudes (possibly including profile retrievals for the TCCON data). 


\section{Introduction}

Atmospheric methane $\left(\mathrm{CH}_{4}\right)$ is the most important anthropogenic greenhouse gas after carbon dioxide. The radiative forcing (RF) from emissions of $\mathrm{CH}_{4}$ for 2011 relative to the preindustrial time (1750) is $0.97 \mathrm{~W} \mathrm{~m}^{-2}$ reflecting a significant contribution to the total anthropogenic RF of $2.29 \mathrm{~W} \mathrm{~m}^{-2}$ (Stocker et al., 2013). There is a diverse range of sources of $\mathrm{CH}_{4}$ emissions from the Earth, coming from biogenic, thermogenic, and pyrogenic formation processes. Among these three groups there are several sources that are driven by anthropogenic activities (livestock breeding, rice cultivation, and exploitation of fossil fuels), whereas other main sources of $\mathrm{CH}_{4}$ are not directly influenced by humans (natural wetlands, biomass burning, termites). However, there are large positive $\mathrm{CH}_{4}$ feedbacks on climate warming such as increased emissions from wetlands and melting hydrates (Dlugokencky et al., 2011). The latter process has attracted special interest because a fast $\mathrm{CH}_{4}$ release from the insulated hydrate reservoir would cause a massive warming effect within a few years (Archer, 2007).

Oxidation of atmospheric $\mathrm{CH}_{4}$ by hydroxyl radicals $(\mathrm{OH})$ is responsible for about $90 \%$ of the global $\mathrm{CH}_{4}$ sink. The remainder is absorbed by soils and by reactions with atomic and chlorine radicals in the stratosphere (Cicerone and Oremland, 1988). Another minor oxidation sink is the reaction with chlorine radicals in the marine boundary layer (Allan et al., 2007).

As a consequence of an imbalance between $\mathrm{CH}_{4}$ sources and sinks, the global $\mathrm{CH}_{4}$ surface concentration has increased to $\sim 1803 \mathrm{ppb}$ (parts per billion) in 2011, thereby exceeding the preindustrial levels by about $150 \%$ (Stocker et al., 2013). Attributing the changes of atmospheric $\mathrm{CH}_{4}$ to source variations on historical timescales (Houweling et al., 2008; Sapart et al., 2012) as well as in the recent past (Bousquet et al., 2006, 2011; Kirschke et al., 2013) has been the subject of extensive research, but is still associated with uncertainties. The ability to locate $\mathrm{CH}_{4}$ emissions (anthropogenic and natural) on regional scales will be essential for future climate policy with regard to emission trading schemes. For this purpose, it is necessary to reduce the transport uncertainties of inversions. Furthermore, it is mandatory to increase the network of $\mathrm{CH}_{4}$ observations and to improve the accuracy of $\mathrm{CH}_{4}$ measurements. Indeed, the spatiotemporal coverage of atmospheric $\mathrm{CH}_{4}$ measurements has been consistently improved since the early 1980s (Kirschke et al., 2013). Global networks for surface-based in situ measurements (i.e., Advanced Global Atmospheric Gases Experiment, AGAGE, and network of National Oceanic and Atmospheric Administration, Earth System Research Laboratory, Global Monitoring Division, NOAA ESRL GMD) have been developed and airborne measurements in the free troposphere have been performed (e.g., Wofsy et al., 2011). Furthermore, remote-sensing measurements of $\mathrm{CH}_{4}$ columns have been achieved by satellite instruments such as
SCIAMACHY (Scanning Imaging Absorption Spectrometer for Atmospheric Cartography) aboard Envisat (Environmental Satellite) and TANSO (Thermal And Near-infrared Sensor for carbon Observation) on GOSAT (Greenhouse Gases Observing Satellite). The ground-based equivalents of the satellite observations are represented by the high-precision Fourier-transform infrared (FTIR) measurements of the two established networks NDACC (Network for the Detection of Atmospheric Composition Change, http://www.ndacc.org/) and TCCON (Total Carbon Column Observing Network, http://www.tccon.caltech.edu/; Wunch et al., 2011a), since both measure the same quantity as satellites.

Because of their high accuracy for column-integrated $\mathrm{CH}_{4}$ measurements, both TCCON (Butz et al., 2011; Schneising et al., 2012; Yoshida et al., 2013; Fraser et al., 2013) and NDACC (Sussmann et al., 2005; De Mazière et al., 2008) data have been used for satellite validation. Satellite retrievals are used extensively in top-down estimates of $\mathrm{CH}_{4}$ emissions (Bergamaschi et al., 2009, 2013; Fraser et al., 2013; Monteil et al., 2013; Houweling et al., 2014), therefore, NDACC/TCCON FTIR retrievals have a strong indirect influence on the accuracy of inversions. In addition, groundbased FTIR measurements can be directly utilized for validation of models (Houweling et al., 2010; Saito et al., 2012; Belikow et al., 2013) and inversions (Fraser et al., 2013). Thus, it is obvious that ground-based FTIR retrievals of columnaveraged $\mathrm{CH}_{4}$ are a cornerstone for satellite retrievals, chemical transport models and inverse models.

By comparing column-averaged dry-air mole fractions of methane $\left(\mathrm{XCH}_{4}\right)$ from NDACC and TCCON retrieved at the sites Garmisch $\left(47.5^{\circ} \mathrm{N}\right)$ and Wollongong $\left(34.5^{\circ} \mathrm{S}\right)$, Sussmann et al. (2013) showed that the data from both networks can be directly combined without performing an intercalibration. Because of its wider spatial and temporal coverage such a joint data set can provide major benefits for validation as well as for long-term trend analysis. However, the agreement obtained between NDACC and TCCON retrievals was not perfect despite applying a refined intercomparison strategy accounting for differing a priori profiles and averaging kernels. The reasons for these residual differences remained unexplained from this previous study.

In this paper we extend the previous work by Sussmann et al. (2013) by updating the FTIR time series and including three additional stations (Ny-Ålesund, $78.9^{\circ} \mathrm{N}$, Karlsruhe, $49.1^{\circ} \mathrm{N}$, and Izaña, $28.3^{\circ} \mathrm{N}$ ), thereby covering diverse geophysical conditions. Besides the intercomparison of NDACC and TCCON measurements, the main focus of this study is understanding the impact of dynamical effects such as stratospheric subsidence and stratosphere-troposphere exchange (STE) processes on the residual differences observed between NDACC and TCCON retrievals of $\mathrm{CH}_{4}$.

Our paper is structured as follows: the participating FTIR sites and their measurement settings are introduced in Sect. 2 along with the MIR (midinfrared) and NIR (near-infrared) retrieval strategies. After explaining the intercomparison strat- 
Table 1. The FTIR stations of this NDACC versus TCCON intercomparison of $\mathrm{XCH}_{4}$, along with geographical coordinates and the time period of FTIR measurements used.

\begin{tabular}{lllll}
\hline Site & latitude & longitude & altitude & time period \\
\hline Garmisch & $47.48^{\circ} \mathrm{N}$ & $11.06^{\circ} \mathrm{E}$ & $0.743 \mathrm{~km}$ & $07 / 2007-12 / 2012$ \\
Wollongong & $34.41^{\circ} \mathrm{S}$ & $150.88^{\circ} \mathrm{E}$ & $0.030 \mathrm{~km}$ & $06 / 2008-12 / 2012$ \\
Izaña & $28.31^{\circ} \mathrm{N}$ & $16.45^{\circ} \mathrm{W}$ & $2.370 \mathrm{~km}$ & $12 / 2010-12 / 2012$ \\
Karlsruhe & $49.08^{\circ} \mathrm{N}$ & $8.43^{\circ} \mathrm{E}$ & $0.110 \mathrm{~km}$ & $04 / 2010-12 / 2012$ \\
Ny-Ålesund & $78.92^{\circ} \mathrm{N}$ & $11.93^{\circ} \mathrm{E}$ & $0.020 \mathrm{~km}$ & $03 / 2005-08 / 2012$ \\
\hline
\end{tabular}

egy the corresponding results are shown in Sect. 3. Section 4 investigates in quantitative terms the impact of dynamical variability on residual differences between MIR and NIR retrievals. This is performed via analysis of one case study showing strong stratospheric subsidence induced by the polar vortex at Ny-Ålesund and another case study for a deep stratospheric intrusion event above Garmisch. Section 5 discusses what can be done to mitigate the impact of stratospheric variability. Finally, Sect. 5 gives a summary and conclusions.

\section{Ground-based soundings of columnar methane in the MIR and NIR}

The NDACC Infrared Working Group currently consists of 22 sites with measurements dating back up to 2 decades. The NDACC retrievals are obtained from solar absorption spectra recorded in the MIR spectral range. Since the establishment of TCCON in 2004, solar absorption measurements in the NIR have started to provide high-precision retrievals of climate gases, such as $\mathrm{CO}_{2}, \mathrm{CH}_{4}$, and $\mathrm{N}_{2} \mathrm{O}$ (Wunch et al., 2011a). Today, there are around 20 operational TCCON sites.

The observational data set obtained from ground-based solar absorption measurements at Garmisch and Wollongong is extended by 1 year from the previous study of Sussmann et al. (2013), until the end of 2012. Additionally, the intercomparison data set is supplemented by FTIR measurements from three further sites (Ny-Ålesund, Karlsruhe, Izaña), thereby covering diverse geophysical conditions (Table 1). The solar FTIR systems of the individual sites are described in Appendix A. The intercomparison of MIR and NIR measurements requires that both MIR and NIR observations are performed in alternating mode.

For the analysis of NDACC- and TCCON-type measurements we used the spectral fitting software SFIT (or PROFFIT) and GFIT, respectively (Pougatchev et al., 1995; Hase et al., 2004; Wunch et al., 2011a). The MIR and NIR retrieval strategies are identical to the strategies used in Sussmann et al. (2013), with the exception of the update from GFIT v.4.4.10 to GFIT v.4.8.6 (GGG2012) which now includes the use of site- and time-dependent a priori profiles. The retrieval strategy MIR-GBM v1.1 (Sussmann et al., 2011) is used for retrieving $\mathrm{XCH}_{4}$ from measurements in the midinfrared spectral region $\left(2613-2921 \mathrm{~cm}^{-1}\right.$ ). Within SFIT (or PROFFIT) a full profile retrieval is set up using a Tikhonov L1 regularization with an altitude-constant regularization strength applied to an a priori profile given in relative units (percent scale). One fixed a priori volume mixing ratio (vmr) profile is used per site, derived from the Whole Atmosphere Chemistry Climate Model (WACCM, version 5, 40-year run; Garcia et al., 2007). The MIR $\mathrm{XCH}_{4}$ is calculated by dividing the retrieved total column by the corresponding dry pressure column. To obtain the daily dry pressure column we used the NCEP (National Center for Environmental Prediction) pressure-temperature-humidity profile from 12:00 UT (universal time) for calculating the air column and water vapor column.

For the NIR retrievals GFIT uses an iterative method of scaling the a priori profile to provide the best fit to the measured spectrum in the near-infrared spectral region (5938$6076 \mathrm{~cm}^{-1}$ ). The retrieved total column is divided by the dry pressure column derived from the simultaneously measured oxygen column (Wunch et al., 2011a) and subsequently scaled by the calibration factor 0.976 . This calibration is used to account for spectroscopic uncertainties and was determined from various campaigns using coincident airborne in situ measurements calibrated to the WMO scale (Wunch et al., 2010; Geibel et al., 2012). The $2 \sigma$ uncertainty of the calibration factor is $\sim 0.2 \%$ and can be regarded as the accuracy of TCCON XCH $\mathrm{X}_{4}$. In contrast to that, MIR retrievals are used without calibration, but are optimized to reduce the seasonal bias due to $\mathrm{H}_{2} \mathrm{O}$ dependence to $<0.14 \%$. The precision of MIR and NIR retrievals estimated on $1 \sigma$ diurnal variation is $<0.3 \%$.

For the MIR retrievals we used HITRAN (HIgh-resolution TRANsmission molecular absorption database) 2000 including the 2001 update release (Rothman et al., 2003). For the NIR retrievals GFIT uses line lists which are based on HITRAN 2004 (Rothman et al., 2004), and HITRAN 2008 (Rothman et al., 2009) including an update by Frankenberg et al. (2008). Further details of the retrieval strategies can be found in Sussmann et al. (2013).

Note that the MIR measurements of Karlsruhe and Izaña were analyzed with the retrieval code PROFFIT instead of SFIT. Differences in these codes are not expected to have an impact on the MIR retrievals as shown by Hase et al. (2004).

\section{Intercomparison}

\subsection{Method}

In addition to the direct intercomparison of MIR and NIR retrievals obtained with their individual retrieval a priori profiles, we will also investigate the intercomparison results after reducing the impact of differing a priori profiles of the MIR versus NIR retrievals. This is achieved by the intercomparison strategy proposed by Sussmann et al. (2013); 
see Eq. (1) therein. This strategy applies two crucial benefits: (i) effects from differing a priori profiles are eliminated by an a posteriori adjustment of the soundings to a common a priori profile $\boldsymbol{x}_{\text {common }}$; and (ii) differing smoothing terms caused by the differing averaging kernels are minimized by using time-dependent and site-dependent profiles $\boldsymbol{x}_{\text {common that are }}$ as close as possible to the true profile $\boldsymbol{x}_{\text {true }}$ at a site at the moment of observation. As in Sussmann et al. (2013) we use 3hourly sampled $\mathrm{CH}_{4}$ model profiles for $\boldsymbol{x}_{\text {common. The model }}$ profiles are provided by the Center for Climate System Research/National Institute for Environmental Studies/Frontier Research Center for Global Change (CCSR/NIES/FRCGC) atmospheric general circulation model (AGCM) based chemical transport model (CTM) (hereafter, ACTM; Patra et al., 2009, 2011). The ACTM simulations are operated at T42 spectral truncation in the horizontal and 67 vertical levels reaching from Earth's surface to the mesosphere $(80 \mathrm{~km})$. See Appendix B in Sussmann et al. (2013) for more details on the ACTM profiles.

Although the use of Eq. (1) in Sussmann et al. (2013) eliminates the impact of differing a priori profiles, differences (MIR-NIR) can still arise because of different vertical sensitivities for both retrievals. The smoothing term for the MIR retrieval is $\left(1-\boldsymbol{a}_{\mathrm{MIR}}^{l}\right)\left(\boldsymbol{x}_{\text {common }}^{l}-\boldsymbol{x}_{\text {true }}^{l}\right)$, where $\boldsymbol{a}_{\mathrm{MIR}}^{l}$ is the total column averaging kernel of the MIR retrieval for model layer $l$. The analogous smoothing term for the NIR retrieval $\left(1-\boldsymbol{a}_{\mathrm{NIR}}^{l}\right)\left(\boldsymbol{x}_{\text {common }}^{l}-\boldsymbol{x}_{\text {true }}^{l}\right)$ is different because in general it holds that $\boldsymbol{a}_{\mathrm{MIR}}^{l} \neq \boldsymbol{a}_{\mathrm{NIR}}^{l}$. This aspect is crucial for understanding the origin of possible residual $\mathrm{XCH}_{4}$ differences (NIR-MIR). The magnitude of such residual $\mathrm{XCH}_{4}$ differences (MIR-NIR) depends on the season because the averaging kernels show zenith angle dependence and, therefore, a seasonal behavior, shown in Fig. 2 in Sussmann et al. (2013). This seasonality of residuals will be discussed in Sect. 3.2 below. The differences are largest when the model differs the most from the true atmospheric profile, which is most likely to occur in special atmospheric situations. Examples for this can be cases with strong stratospheric subsidence or stratospheric intrusions. Case studies that illustrate this effect will be discussed in quantitative terms in Sect. 4 .

The intercomparison is based on monthly means calculated from individual MIR and NIR measurements recorded on the same day. Only months with $>5$ MIR and $>5$ NIR measurements have been included. The criterion of daily coincidence ensures that the results of the monthly mean intercomparison will also reflect the agreement between NIR and MIR retrievals on daily and shorter timescales.

\subsection{Results}

Figure 1a shows a scatter plot of the MIR and NIR monthly means containing data from all five FTIR sites as retrieved with their original retrieval a priori profiles. Error bars on data points are $2 \sigma$ uncertainties derived from the standard deviation (SD) of the linear slope fit $(2 \mathrm{SD} / \sqrt{ } 2)$ determined
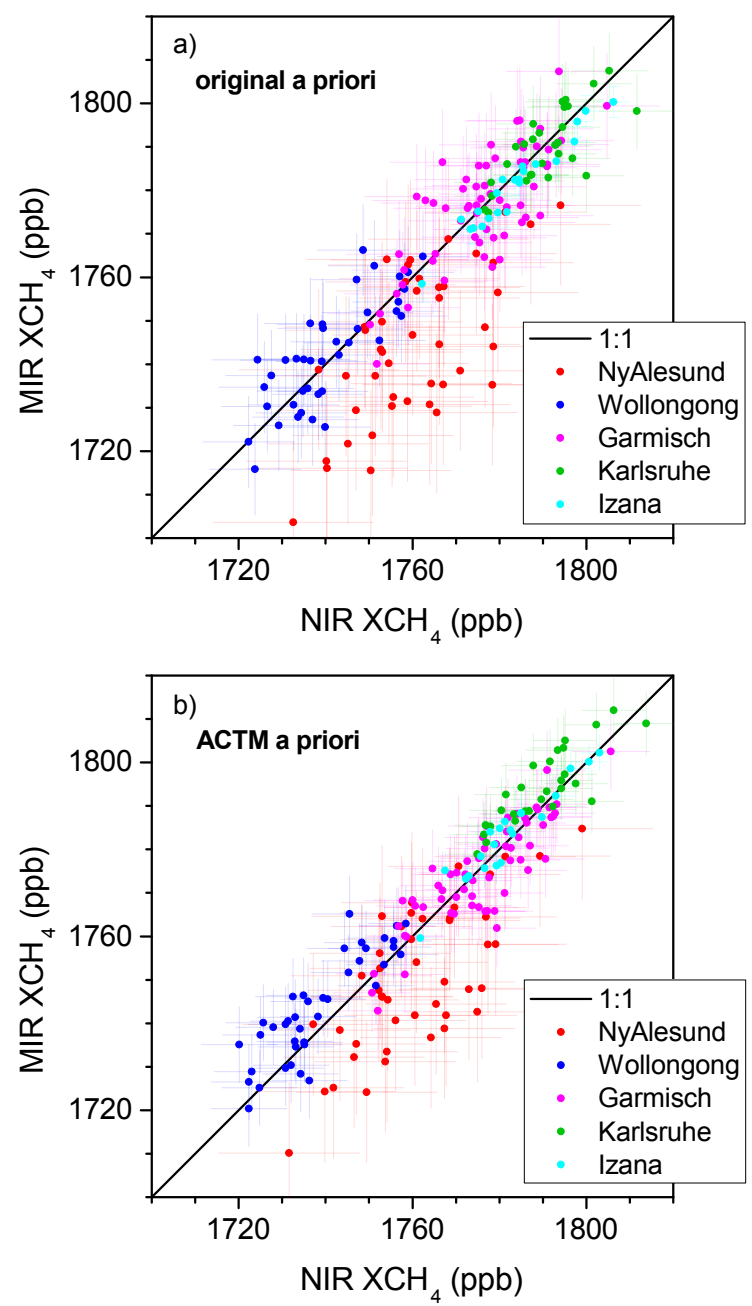

Figure 1. (a) Scatter plot of MIR and NIR monthly means, both series retrieved with the standard retrieval a priori profiles. Error bars on data points are $2 \sigma$ uncertainties derived from the SD of the linear slope fit $(2 \mathrm{SD} / \sqrt{ } 2)$. (b) Same as (a) but for using ACTM profiles as common prior.

separately for each site, see Sussmann et al. (2013) for a discussion of this error characterization. The linear MIR/NIR slopes and their corresponding $2 \sigma$ uncertainties are obtained from linear fits forced through zero. Consecutively, the slope uncertainty is illustrated behind the slope value in brackets corresponding to the third and fourth decimal place of the slope value. The linear MIR/NIR slopes (obtained from linear fits forced through zero) are not significantly different from 1 for three stations; i.e., 1.0002(12) for Garmisch, 1.0010(13) for Wollongong and 0.9996(13) for Karlsruhe, see Table 2 . However, they are significantly different from 1 for Izaña $(0.9986(06))$ and for Ny-Ålesund $(0.9909(22))$. The slope for Izaña corresponds to a small bias in $\mathrm{XCH}_{4}(1.4 \%$ o) whereas there is a relatively big bias for Ny-Ålesund of $9.1 \%$. This means that the results of the direct intercomparison confirm the conclusion of Sussmann et al. (2013), that 
the MIR and NIR data sets could be used together without the need of an intercalibration (except for $\mathrm{Ny}$ - $\AA^{\circ}$ lesund; possible reasons will be discussed in Sect. 4).

Figure $1 \mathrm{~b}$ is the same as Fig. 1a but using ACTM profiles as common prior. The linear MIR/NIR slopes (obtained from linear fits forced through zero) are not significantly different from 1 for Garmisch (0.9994(09)) and Izaña (1.0007(07)). However, the MIR/NIR slopes are different from 1 for Karlsruhe (1.0024(11)), Wollongong (1.0030(11)), and NyAlesund (0.9940(19)). It is not obvious that there is a significant improvement in the overall agreement of the MIR and $\mathrm{NIR} \mathrm{XCH}_{4}$ monthly means after the adjustment to the common prior, except at Ny-Ålesund, where the difference of the linear slope from 1 is reduced (from 0.9909(22) to $0.9940(19)$ ) corresponding to a bias of $6 \%$. However, as explained in Sussmann et al. (2013) the main benefit of using the common ACTM a priori is that the seasonalities of the MIR and NIR $\mathrm{XCH}_{4}$ time series are in a better agreement.

The MIR and NIR monthly mean time series for all stations are shown in Fig. $2 \mathrm{a}-\mathrm{j}$, retrieved with both their original retrieval a priori profiles and with the common ACTM prior profile. It can be seen that for all stations except Izaña the SD of the difference time series (Fig. 2a-j, upper trace) is reduced by using the ACTM profiles as common prior. For Izaña there is no reduction of the SD (Fig. 2j) because the MIR and NIR time series are already in very good agreement $(\mathrm{SD}=2.5 \mathrm{ppb})$ without applying the a posteriori adjustment to a common a priori profile (Fig. $2 \mathrm{i}$ ). This is probably due to generally favorable measurement conditions at Izaña with a high fraction of days with unperturbed clear sky conditions. An overview of all SDs and MIR/NIR slopes is given in Table 2 .

Although the use of ACTM as a common prior leads to an improved agreement between MIR and $\mathrm{NIR} \mathrm{XCH}_{4}$, there are still differences which can reach levels of up to $30 \mathrm{ppb}$ for Ny-Ålesund (Fig. 2b), 20 ppb for Wollongong (Fig. 2d), $18 \mathrm{ppb}$ for Garmisch (Fig. 2f), and $12 \mathrm{ppb}$ for Karlsruhe (Fig. 2h). Furthermore, Fig. 2 shows a periodicity in the occurrence of the maximum differences at all stations except Izaña.

A principal explanation for such seasonal differences (MIR-NIR) has been given in Sect. 3.1; i.e., ACTM profiles cannot completely resolve the local dynamical variability caused by atmospheric processes such as stratospheric subsidence or stratosphere-troposphere exchange processes. In order to investigate this effect in quantitative terms, in the following section we present a case study of stratospheric subsidence induced by the polar vortex at $\mathrm{Ny}$-Ålesund and another case study of a deep stratospheric intrusion event at Garmisch. In addition to that, in Sect. 5 we discuss the potential of different methods to mitigate the impact caused by stratospheric variability.

\section{Effects of dynamical variability}

\subsection{Impact of subsidence}

The motivation for this case study is to demonstrate and explain the effects of polar subsidence on the MIR and NIR retrievals (Sect. 4.1.1). Furthermore, the total impact on the intercalibration results for $\mathrm{Ny}$-Ålesund is inferred by excluding FTIR measurements that are affected by polar vortex subsidence (Sect. 4.1.2).

\subsubsection{Case study I: Ny-Ålesund on 25 March 2011}

As shown by Lindenmaier et al. (2012) and Sinnhuber et al. (2011) the meteorological conditions during winter/spring 2011 formed a strong polar vortex that persisted into April. Besides that, high potential vorticity (PV) values of 46 PVU (potential vorticity unit) on the $450 \mathrm{~K}$ potential temperature (PT) surface (ECMWF reanalysis, European Centre for Medium-Range Weather Forecasts) strongly indicate that $\mathrm{Ny}$-Alesund was underneath the area of the polar vortex on 25 March 2011.

Therefore, we investigate the impact of replacing the ACTM-based a priori profile with a strongly subsided $\mathrm{CH}_{4}$ profile, which is typical for intravortex conditions and may be more realistic for 25 March 2011 above Ny-Ålesund. Such a

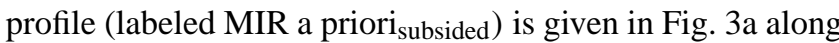
with the ACTM profile for 25 March 2011 and the standard retrieval a priori profiles. This subsided profile corresponds to the MIR standard retrieval a priori from WACCM, which has been modified to account for subsidence according to Toon et al. (1992), see Appendix B for details.

Figure 4 shows the MIR and NIR $\mathrm{XCH}_{4}$ as computed using the original ACTM as common prior along with the case

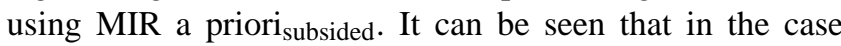
of using the original ACTM as a common prior, there is a significant difference between the NIR and MIR retrievals ( $\sim 29$ ppb for the time period 08:00-10:00 UT), while there is good agreement if using the subsided profile MIR a priori $_{\text {subsided }}$ (mean difference of $\sim 6 \mathrm{ppb}$ for the time period 08:00-10:00 UT). Most of the difference arises from the fact that the NIR data based on the ACTM prior profile are reduced by $\sim 31 \mathrm{ppb}$ (for the time interval 08:00-10:00 UT) if

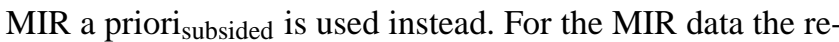

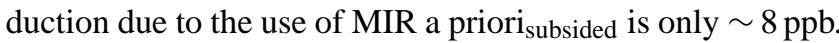
This is due to the fact that the NIR total column kernels are not as sensitive as the MIR total column kernels in the lower stratosphere (see Fig. 3b). Figure C1 shows an analogous plot with the MIR and NIR retrievals based on their original standard a priori profiles. The effect of using the subsided profile (MIR a priori subsided $_{\text {) instead of the original standard retrieval }}$ a priori profiles is very similar to the effect described with regard to Fig. 4; i.e., the difference between the NIR and MIR retrievals is reduced from $\sim 37$ to $\sim 6 \mathrm{ppb}$ (for the time period 08:00-10:00 UT). Furthermore, MIR and NIR retrievals 
Table 2. Slope of linear scatter plot fits between multiannual data sets of NIR and MIR $\mathrm{XCH}_{4}$ retrievals using varied a priori profiles. Slope uncertainties are derived from the fit and are at $2 \sigma$. The slope uncertainty is illustrated in brackets corresponding to the third and fourth decimal place of the slope value; i.e., (12) implies a slope uncertainty of \pm 0.0012 . Standard deviations of NIR-MIR differences are provided as SD. Data are monthly means constructed from same-day measurement coincidences.

\begin{tabular}{lllll}
\hline \multirow{2}{*}{ Data set } & \multirow{2}{*}{ a priori } & \multicolumn{3}{c}{ fit $y=b x$} \\
\cline { 3 - 5 } & & $\begin{array}{l}\text { slope } b \text { and } \\
2 \sigma \text { uncertainty }\end{array}$ & $\begin{array}{l}\text { slope different from } \\
1 \text { on } 2 \sigma \text { level? }\end{array}$ & SD (ppb) \\
\hline Garmisch & NIR \& MIR retrieved with original a priori & $1.0002(12)$ & no & 8.6 \\
& NIR \& MIR corrected to ACTM a priori & $0.9994(09)$ & no & 6.3 \\
\hline Wollongong & NIR \& MIR retrieved with original a priori & $1.0010(13)$ & no & 7.4 \\
& NIR \& MIR corrected to ACTM a priori & $1.0030(11)$ & yes & 6.1 \\
\hline Izaña & NIR \& MIR retrieved with original a priori & $0.9986(06)$ & yes & 2.5 \\
& NIR \& MIR corrected to ACTM a priori & $1.0007(07)$ & no & 3.0 \\
\hline Karlsruhe & NIR \& MIR retrieved with original a priori & $0.9996(13)$ & no & 6.1 \\
& NIR \& MIR corrected to ACTM a priori & $1.0024(11)$ & yes & 5.1 \\
\hline Ny-Ålesund & NIR \& MIR retrieved with original a priori & $0.9909(22)$ & yes & 13.0 \\
& NIR \& MIR corrected to ACTM a priori & $0.9940(19)$ & yes & 11.5 \\
\hline
\end{tabular}

are reduced by 4 and $35 \mathrm{ppb}$, respectively, compared to the standard a priori profiles.

Our case study for Ny-Ålesund shows in quantitative terms that the effect of polar subsidence on $\left(\boldsymbol{x}_{\text {common }}^{l}-\boldsymbol{x}_{\text {true }}^{l}\right)$ can be high enough to significantly impact the accuracy of the MIR and NIR retrievals in a different way. Especially, the NIR retrievals are significantly affected when using a priori profiles which do not account for stratospheric subsidence, because their averaging kernels are less sensitive in the stratosphere.

\subsubsection{Exclusion of subsidence events}

While the case study in Sect. 4.1.1 was focused on the different impacts of stratospheric subsidence on the MIR and NIR retrievals for a single day, we now investigate the overall impact of subsidence on the full $\mathrm{Ny}$-Ålesund time series used for the intercomparison of MIR and NIR $\mathrm{XCH}_{4}$ retrievals.

To identify the location of the polar vortex and the onset and breakup dates of the vortex, we used the criteria from Nash et al. (1996). Thereby, we determined if Ny-Ålesund was inside the vortex or not at the $450 \mathrm{~K}$ potential temperature level (about $18 \mathrm{~km}$ altitude). Figure 5 shows the number of FTIR measurement days at Ny-Ålesund that were influenced by the polar vortex together with the total number of FTIR measurement days, separated by year. As FTIR measurements (MIR and NIR) at Ny-Ålesund are typically performed from the middle of March until the end of September, the overlap time with the polar vortex period is limited to early spring. We found that the relative fraction of FTIR measurement days influenced by the polar vortex is $\sim 63 \%$ in March and $\sim 57 \%$ in April (averaged for the time period 2005-2012).
All in all, $23 \%$ of the FTIR measurement days were influenced by the polar vortex. These days were excluded from the MIR/NIR intercomparison and monthly mean scatter plots (MIR versus NIR) were analyzed via linear fits. The parameters from these fits are listed in Table 3. The linear MIR/NIR slope of the data set that is corrected to ACTM as common prior is improved slightly from $0.9940(19)$ to $0.9950(20)$ and the SD is further reduced from 11.5 to $11.0 \mathrm{ppb}$.

Despite these slightly positive effects of the exclusion of polar vortex situations on the overall intercomparison, there are still significant residual $\mathrm{XCH}_{4}$ differences (MIR-NIR) for Ny-Ålesund, which vary temporally (see Fig. C2). Hence, we speculate that deviations of the ACTM profiles from the true profiles in the stratosphere also occur outside the early spring period. Indeed, besides subsidence, there are further dynamical processes in the UTLS (upper troposphere/lower stratosphere) region that may contribute to a variability of the $\mathrm{CH}_{4}$ profile not captured by ACTM. This assumption is supported by the fact that the residual $\mathrm{XCH}_{4}$ differences from the stations Garmisch, Wollongong, and Karlsruhe cannot be linked to the polar vortex subsidence because of their geographical position. Therefore, the emphasis of Sect. 4.2 lies on the impact of dynamical variability caused by STE processes. Moreover, systematic deviations of the a priori profiles in the stratospheric $\mathrm{CH}_{4}$ could also act as a source for smoothing effects.

\subsection{Impact of stratosphere-troposphere exchange processes}

STE processes cause the transport of air-masses across the tropopause. For a detailed overview of the extensive research 

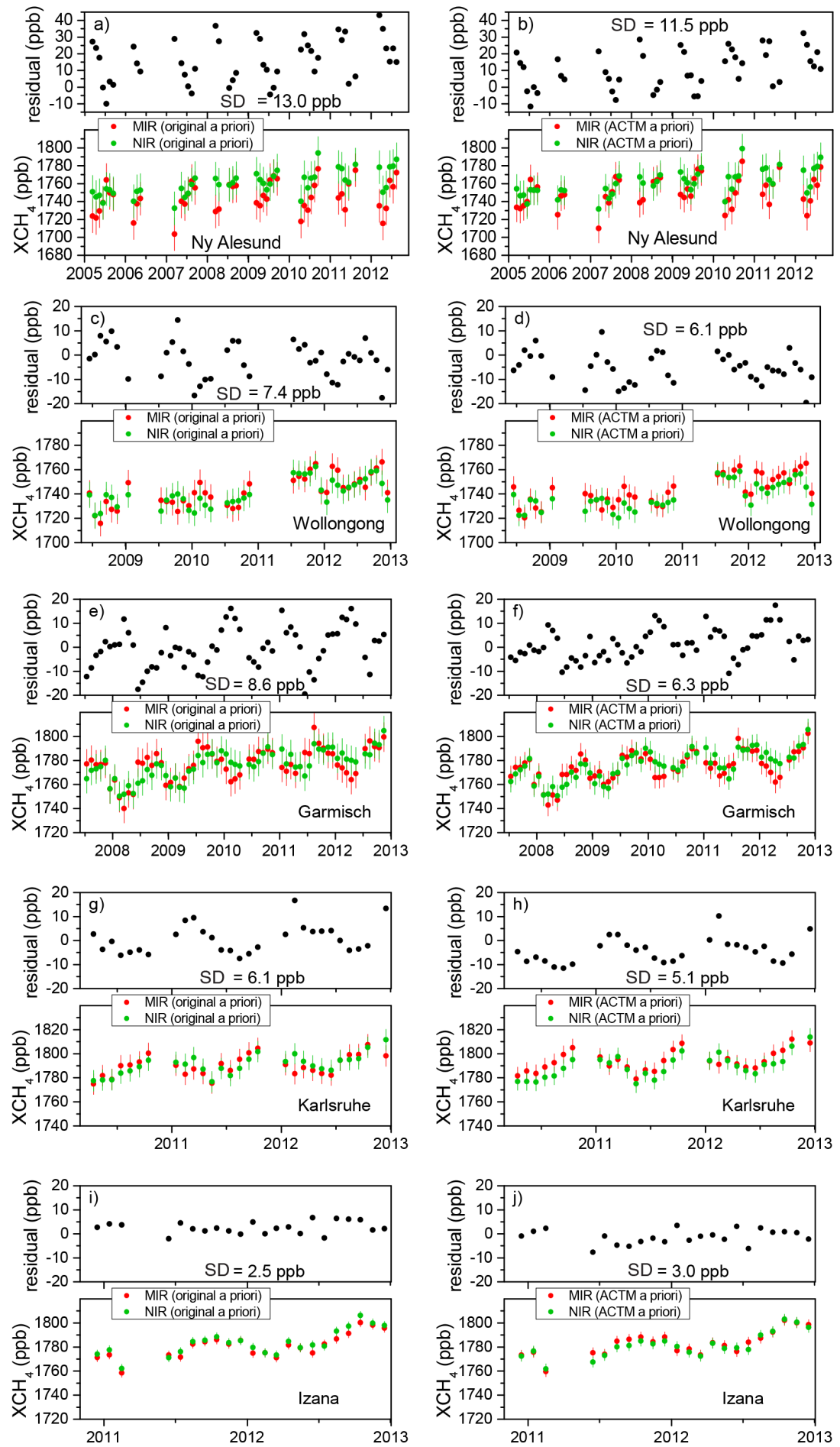

Figure 2. (a) Lower trace: monthly-mean MIR and NIR time series for Ny-Ålesund. Both column series are plotted as retrieved with their original retrieval a priori profiles. Error bars are $2 \sigma$ uncertainties as explained in Fig. 1. Upper trace: residual time series; i.e., difference time series of the NIR and MIR data shown in the lower trace. (b) Same as (a) but using for Ny-Ålesund a correction to 3-hourly ACTM profiles as common prior, (c) for Wollongong the original retrieval a priori profiles, (d) for Wollongong a correction to ACTM, (e) for Garmisch the original retrieval a priori profiles, (f) for Garmisch a correction to ACTM, (g) for Karlsruhe the original retrieval a priori profiles, (h) for Garmisch a correction to ACTM, (i) for Izaña the original retrieval a priori profiles, and (j) for Izaña a correction to ACTM. 
Table 3. As Table 2, but only for Ny-Ålesund. The data set "Ny-Ålesund PV filter" corresponds to MIR and NIR retrievals that are not influenced by the polar vortex.

\begin{tabular}{lllll}
\hline & & \multicolumn{2}{c}{ fit $y=b x$} \\
\cline { 3 - 5 } Data set & a priori & $\begin{array}{l}\text { slope } b \text { and } \\
2 \sigma \text { uncertainty }\end{array}$ & $\begin{array}{l}\text { slope different from } \\
1 \text { on } 2 \sigma \text { level? }\end{array}$ & SD (ppb) \\
\hline Ny-Ålesund & NIR \& MIR retrieved with original a priori & $0.9909(22)$ & yes & 13.0 \\
Ny-Ålesund PV filter & NIR \& MIR retrieved with original a priori & $0.9922(23)$ & yes & 12.4 \\
Ny-Ålesund & NIR \& MIR corrected to ACTM a priori & $0.9940(19)$ & yes & 11.5 \\
Ny-Ålesund PV filter & NIR \& MIR corrected to ACTM a priori & $0.9950(20)$ & yes & 11.0 \\
\hline
\end{tabular}
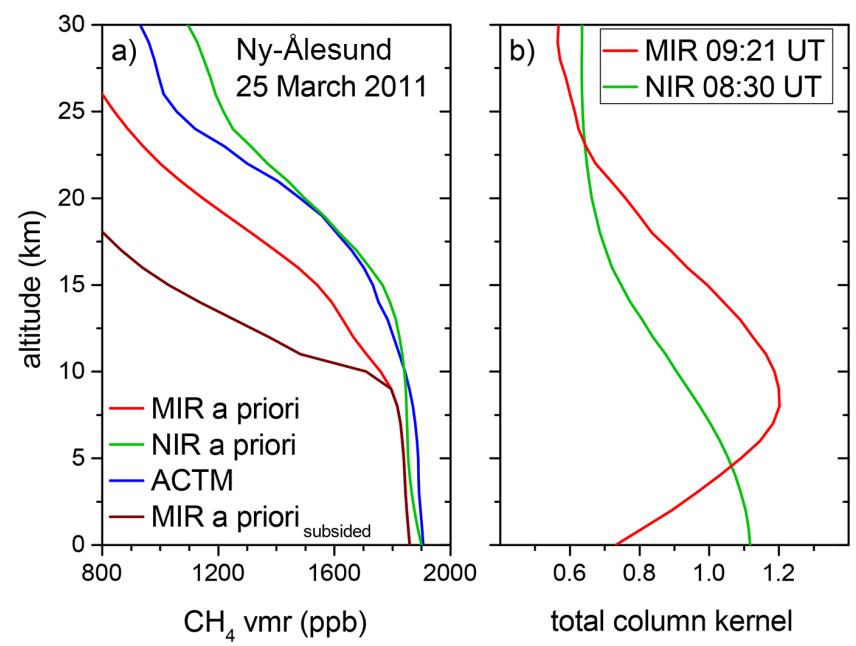

Figure 3. (a) A priori profiles used for analysis of Ny-Ålesund spectra recorded on 25 March 2011. MIR a priori is the standard a priori profile from WACCM for Ny-Ålesund used in SFIT. NIR a priori is the current a priori profile of GFIT (release ggg_2012_July_Update) for Ny-Ålesund. ACTM is the actual ACTM profile for 25 March 2011 used as a common prior for standard intercomparison of the NIR and MIR retrievals. MIR a priori $_{\text {subsided }}$ is a strongly subsided profile typical for intravortex conditions as explained in Appendix B used for recorrection of the NIR and MIR retrievals in a more realistic intercomparison. (b) Averaging kernels for MIR and NIR retrievals using Ny-Ålesund spectra recorded on 25 March 2011.

related to STE processes with some focus on processes in the extratropics we refer to Stohl et al. (2003). A considerable part of STE research dealt with the impacts of STE on the tropospheric ozone $\left(\mathrm{O}_{3}\right)$ budget due to its relevance to air quality (Stohl and Trickl, 1999; Stohl et al., 2000; Trickl et al., 2003, 2010). Recently, by using a high-resolution chemical transport model Lin et al. (2012) were able to show that stratospheric intrusions in springtime of 2010 significantly increased surface ozone at high-elevation western US sites.

Whereas ozone-related STE processes have been well studied, the impact of STE processes on the $\mathrm{CH}_{4}$ budget has not been investigated very much. Nevertheless, by observing a stratospheric intrusion event on 27 March 2010, Xiong et

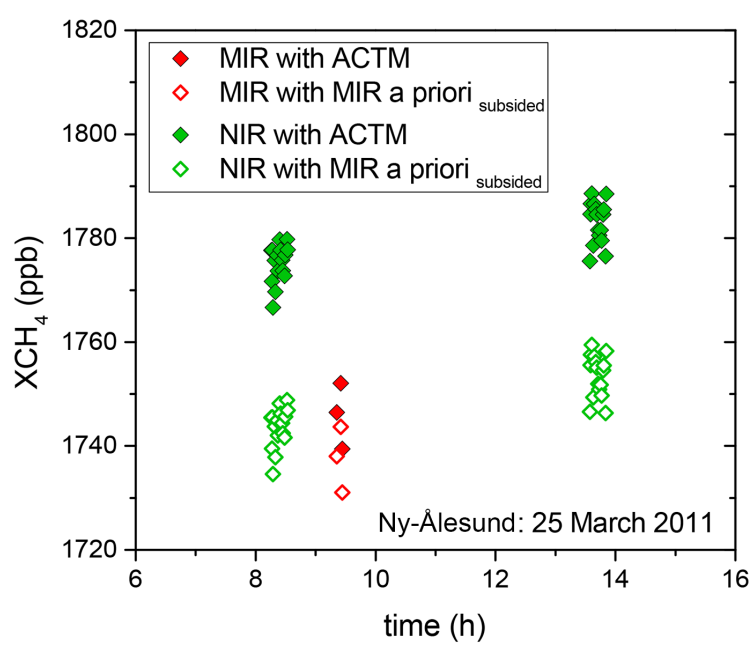

Figure 4. $\mathrm{Ny}$-Ålesund $\mathrm{XCH}_{4}$ on 25 March 2011 retrieved from FTIR data. MIR and NIR retrievals are corrected to the common ACTM prior (filled squares) and are corrected to a strongly subsided MIR a priori profile (open squares) as shown in Fig. 3a.

al. (2013) revealed that areas with depleted $\mathrm{CH}_{4}$ are collocated with enhanced $\mathrm{O}_{3}$ and low tropopause. They analyzed data from Atmospheric Infrared Sounder (AIRS) retrievals and used aircraft in situ measurements that confirmed that $\mathrm{CH}_{4}$ depletion occurred down to $550 \mathrm{hPa}$ with a decrease in mixing ratios of up to $100 \mathrm{ppb}$.

In order to investigate the (possibly differing) impact of STE processes on MIR and NIR retrievals of $\mathrm{XCH}_{4}$, Sect. 4.2.1 deals with a stratospheric intrusion event on 6 March 2008 at Garmisch. After that, the aim of Sect. 4.2.2 is to estimate the percentage of FTIR measurements that are affected by STE processes, and to identify the consequences for the intercomparison of MIR and NIR retrievals at Garmisch.

\subsubsection{Case study II: Garmisch on 6 March 2008}

Figure 6a shows the single MIR and NIR $\mathrm{XCH}_{4}$ values on 6 March 2008 as computed with the a posteriori adjustment to the common ACTM prior. It is obvious that the agreement 


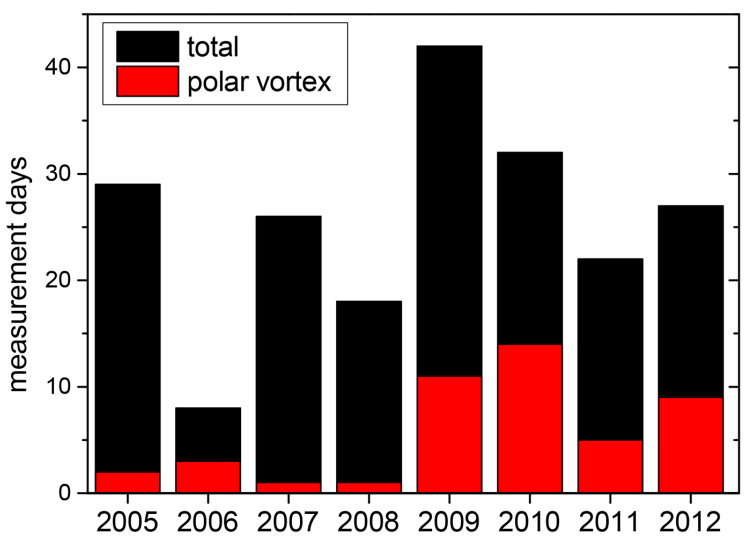

Figure 5. Number of days with coincident MIR and NIR FTIR measurements at Ny-Ålesund. Black: total number; red: only measurement days when the station has been inside the polar vortex.

between MIR and NIR $\mathrm{XCH}_{4}$ is very good until 11:00 UTC (universal time coordinated), but then the NIR $\mathrm{XCH}_{4}$ increases by about $25 \mathrm{ppb}$ within $1 \mathrm{~h}$. In contrast to that, the MIR $\mathrm{XCH}_{4}$ increases only slightly, and this results in high $\mathrm{XCH}_{4}$ residuals (NIR-MIR $\sim 15 \mathrm{ppb}$ ).

We will show in the following that this significant increase in $\mathrm{XCH}_{4}$ differences within a short timescale of $1 \mathrm{~h}$ is caused by a deep stratospheric intrusion event that was observed by the tropospheric ozone lidar at Garmisch. Details and illustrations of lidar sounding series detecting stratospheric intrusions very similar to our 6 March 2008 case can be found, e.g., in Trickl et al. (2010). The lidar sounding series of 6 March 2008 (Trickl et al., 2014) points to the occurrence of various layers with elevated ozone levels generated by a stratospheric intrusion. Until 11:00 UTC, there is one layer existing approximately in the altitude range of $2-4 \mathrm{~km}$ and a second layer in the range of 6-10 km. Both regions are characterized by enhanced $\mathrm{O}_{3}$ volume mixing ratios (typically up to $125 \mathrm{ppb}$ ). These layers with elevated ozone concentrations correspond to areas of depleted $\mathrm{CH}_{4}$ volume mixing ratios. According to the lidar sounding, after 11:00 UTC there remains only one layer with ozone-rich air masses, i.e., $\mathrm{CH}_{4}$ depleted air masses in the UTLS region $(8-15 \mathrm{~km})$.

To respond to the dynamical variability induced by the stratospheric intrusion the MIR and NIR retrievals were recorrected (Fig. 6b). The ACTM profiles were modified in a simple manner to represent the depletion of $\mathrm{CH}_{4}$ before 11:00 UTC (ACTM intrusion1 $)$ and after 11:00 UTC (ACTM $\mathrm{Antrusion2}_{2}$. The magnitudes of the $\mathrm{CH}_{4}$ depletions used in Fig. 7a correspond to typical values reported in the study by Xiong et al. (2013).

The transformation of $\mathrm{O}_{3}$ lidar soundings into $\mathrm{CH}_{4}$ profiles is just a semiquantitative approach. However, the recorrection of the MIR and NIR retrievals to the modified ACTM a priori profiles of Fig. 7a results in a nearly perfect agreement between MIR and NIR $\mathrm{XCH}_{4}$ as shown
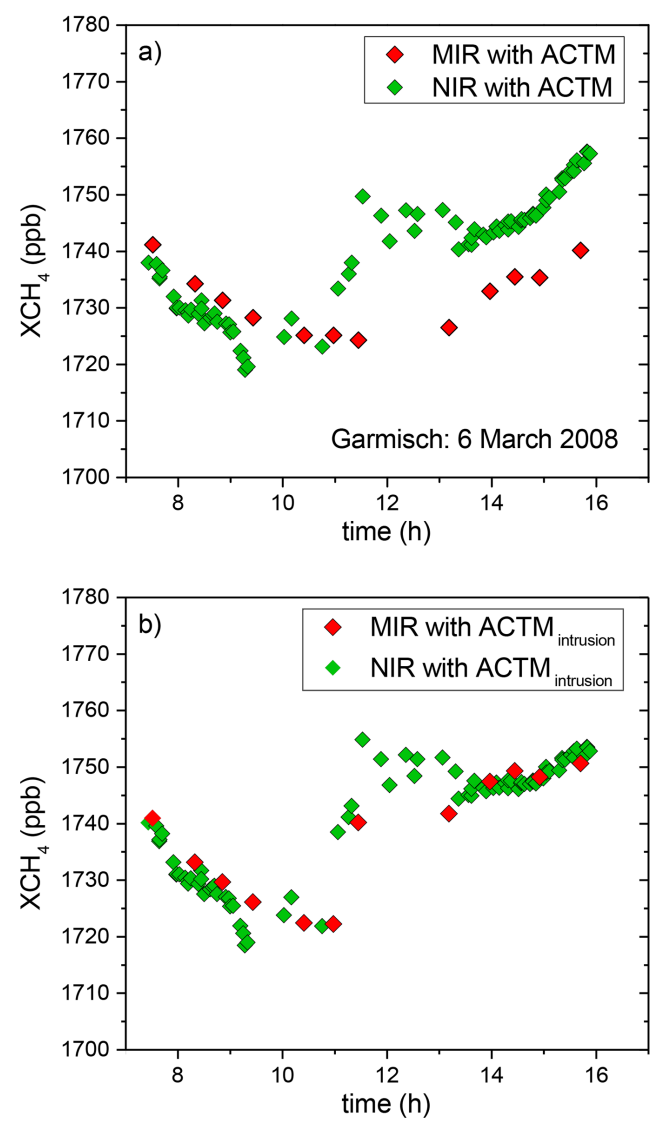

Figure 6. Garmisch $\mathrm{XCH}_{4}$ on 6 March 2008 retrieved from FTIR data. (a) MIR and NIR retrievals are corrected to a common ACTM a priori. (b) MIR and NIR retrievals are corrected to the modified ACTM profiles shown in Fig. 7a.

in Fig. 6b. The recorrection effect on the NIR retrievals is small $(<5 \mathrm{ppb})$ because the NIR total column retrievals shows high sensitivity in the troposphere and the lowest stratosphere (see Fig. 7b). The effect on the MIR retrievals, however, is twofold: Although the MIR total column kernels are not perfectly sensitive in the troposphere (Fig. 7b) there is almost no recorrection effect on the MIR retrievals until 11:00 UTC. This is because of two smoothing effects, which compensated each other before the recorrection was applied. The lower-layer $\mathrm{CH}_{4}$ depletion (Fig. 7a, ACTM $_{\text {intrusion 1 }}, 2-4 \mathrm{~km}$ ) was underestimated (see MIR averaging kernel in Fig. 7b) while the upper-layer $\mathrm{CH}_{4}$ depletion (Fig. 7a, ACTM intrusion1 $_{1}, 6-10 \mathrm{~km}$ ) was overestimated (see MIR averaging kernel in Fig. 7b). Therefore, there was no net effect on the MIR retrievals before 11:00 UTC. However, after 11:00 UTC, MIR $\mathrm{XCH}_{4}$ was significantly lower than NIR $\mathrm{XCH}_{4}$ because of an overestimation of the $\mathrm{CH}_{4}$ depletion in the UTLS region (Fig. 7a, ACTM intrusion2, $8-15 \mathrm{~km}$; see MIR averaging kernel in Fig. 7b). The recorrection effect on MIR retrievals after 11:00 UTC corresponds to an increase in $\mathrm{XCH}_{4}$ of up to $15 \mathrm{ppb}$. All together, we are able to explain 

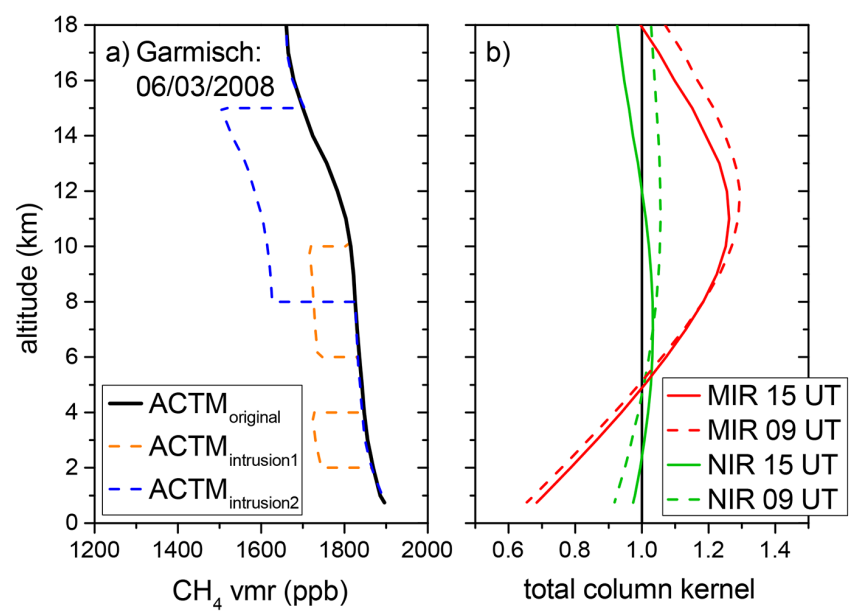

Figure 7. (a) ACTM profiles used for the a posteriori correction of MIR and NIR retrievals of Garmisch spectra recorded on 6 March 2008: ACTM $_{\text {original }}$ is the original ACTM profile used in the correction. $\mathrm{ACTM}_{\text {intrusion1 }}$ and $\mathrm{ACTM}_{\text {intrusion2 }}$ are the original ACTM profiles which were modified due to a deep stratospheric intrusion event on this day. $\mathrm{ACTM}_{\text {intrusion1 }}$ is used for the recorrection of retrievals before 11:00 UTC, ACTM intrusion2 $_{\text {is }}$ used for the recorrection of retrievals after 11:00 UTC. (b) Averaging kernels for MIR and NIR retrievals of Garmisch spectra recorded on 6 March 2008 .

the diurnal variation of the recorrected MIR and NIR $\mathrm{XCH}_{4}$ (Fig. 6b) in relation to the basic features of the stratospheric intrusion above Garmisch.

Finally, we can understand the significant step in both MIR and NIR $\mathrm{XCH}_{4}$ which can be seen after 11:00 UTC. The two tropospheric layers of $\mathrm{CH}_{4}$-depleted air in the time period until their dissipation at 11:00 UTC have a bigger impact on $\mathrm{XCH}_{4}$ compared to the $\mathrm{CH}_{4}$ depletion in the UTLS after 11:00 UTC because the relative fraction of air mass is higher in the troposphere. Therefore, the mean $\mathrm{XCH}_{4}(\mathrm{NIR}$, MIR) before 11:00 UTC is about $20 \mathrm{ppb}$ lower than for the time period after 11:00 UTC. This is the first time that such a significant intraday increase in $\mathrm{XCH}_{4}(1.15 \%)$ could be detected from ground-based FTIR retrievals and explained by the dynamical variability of a stratospheric intrusion event.

\subsubsection{Exclusion of STE events}

For the detection of stratospheric intrusions coincident with FTIR measurements at Garmisch we adapted an approach for the analysis of stratospheric intrusions that was introduced by Trickl et al. (2010). This strategy uses STE trajectories based on ECMWF data. These STE trajectories represent a small subset of 4-day forward trajectories calculated with the Lagrangian analysis tool (LAGRANTO; Wernli and Davies, 1997) and are defined through two requirements: they are (i) initially residing in the stratosphere and then (ii) during the following 4 days are descending by more than $300 \mathrm{hPa}$ into the troposphere.

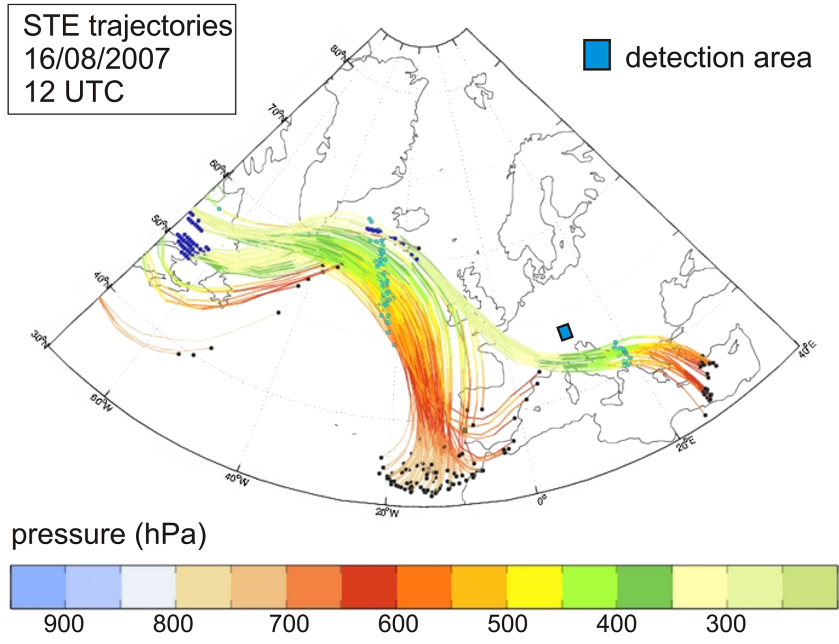

Figure 8. STE trajectories calculated with the tool of ETH Zürich, based on ECMWF data. The trajectories were initiated on $16 \mathrm{Au}-$ gust 2007 at $t_{0}=12: 00$ UTC. The time positions on the trajectories for $t_{0}, t_{0}+2 \mathrm{~d}$ and $t_{0}+4 \mathrm{~d}$ are marked by azure, cyan, and black dots, respectively. The frame of the detection area $\left(2^{\circ} \times 2^{\circ}\right)$ around Garmisch is marked by the blue square.

For each day, STE trajectories have been calculated for the start times 00:00 and 12:00 UTC, and distributed by automated electronic mail by ETH Zürich (Swiss Federal Institute of Technology). As an example, Fig. 8 shows the intrusion trajectories initiated on 16 August 2007 at 12:00 UTC. For the identification of the stratospheric intrusions at Garmisch we defined a detection area of $\pm 1^{\circ}$ (latitude and longitude) around Garmisch (see Fig. 8 blue square). The trajectories in Fig. 8 do not touch or pass through the detection area because, most likely, there will not be a STE event at Garmisch for the next 4 days. As a further requirement for counting a stratospheric intrusion, at least five trajectories should touch or hit the detection area.

In addition, trajectory calculations were carried out with the HYSPLIT (Hybrid Single Particle Lagrangian Integrated Trajectory) model. The HYSPLIT trajectories were evaluated according to the approach by Trickl et al. (2010, Sect. 2.3 therein) for identifying stratospheric intrusions at Garmisch. (Note that the detection analysis of stratospheric intrusions could not be made for the complete FTIR data set because of some missing trajectories. Nevertheless, the analysis covers the majority of the FTIR measurements.)

Our analysis reveals that $\sim 35 \%$ of the FTIR measurement days at Garmisch are influenced by STE processes. When excluding the affected $\mathrm{XCH}_{4}$ data the agreement is improved significantly for the original a priori case with regard to the SD of difference time series NIR-MIR: using the original and common ACTM priors (see Fig. C3) it is reduced from 8.2 to $6.5 \mathrm{ppb}$ and from 6.2 to $4.7 \mathrm{ppb}$, respectively. The MIR/NIR slope from the intercomparison with original prior (Fig. 9a) is not improved, but is still in the range of TCCON 

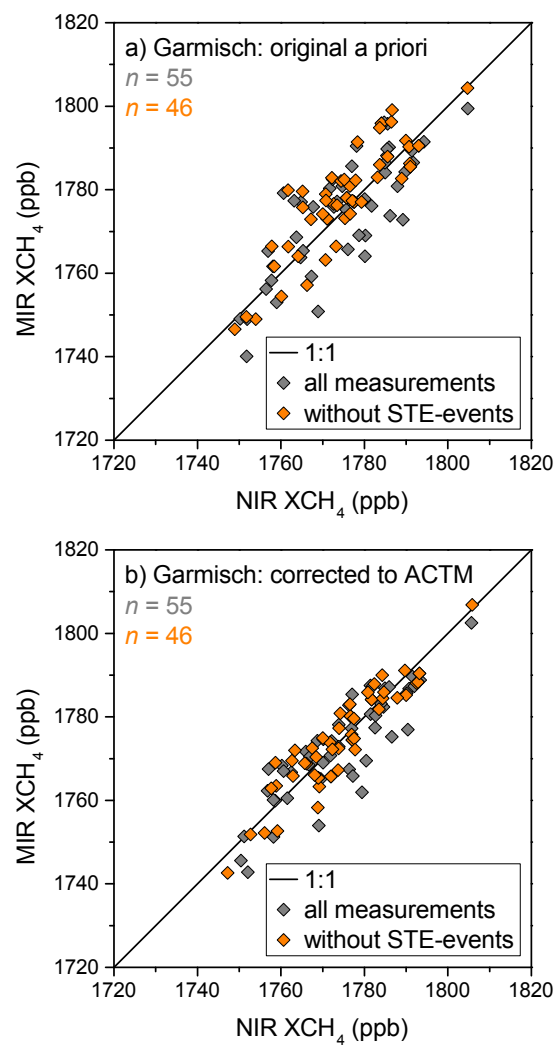

Figure 9. Scatter plot of MIR and NIR monthly means for Garmisch $\mathrm{XCH}_{4}$ obtained from all FTIR measurements (black diamonds) and FTIR measurements which are not affected by STE events (red diamonds), respectively. (a) MIR and NIR $\mathrm{XCH}_{4}$ retrieved with their original retrieval a priori profiles and (b) a posteriori corrected to common ACTM profiles. Note: the data set is not identical to that in Sect. 3 because STE trajectories are not available for the complete time series.

accuracy. In the case of the common prior profile (Fig. 9b), the MIR/NIR slope is slightly improved by the exclusion of affected data. All fit parameters for the data sets of the STE analysis at Garmisch are given in Table 4.

The improved agreement is achieved by the fact that measurement days with high residual $\mathrm{XCH}_{4}$ differences, caused by different smoothing terms related to STE, are filtered out. Winter months are particularly affected by this extra filter criterion. This is in accordance with Sprenger and Wernli (2003), who showed that STE in the Northern Hemisphere has a distinct seasonal cycle with a flat maximum from December to April and a pronounced minimum in August and September.

Another outcome from Sprenger and Wernli (2003) is that at a subtropical site like Izaña, the frequency of STE events is much lower than at midlatitude sites like Garmisch, Karlsruhe, or Wollongong. Hence, the overall impact of STE processes on Izaña MIR and NIR retrievals is small compared to the other sites. This is confirmed by the very good agreement between MIR and NIR seasonalities at Izaña. Also, the polar site Ny-Ålesund is more influenced by STE processes than Izaña and thereby the MIR and NIR retrievals at Ny-Ålesund are affected by a second mechanism of dynamical variability in addition to polar subsidence. Besides that, we expect that remaining $\mathrm{XCH}_{4}$ differences (NIR - MIR) are caused by near-surface $\mathrm{CH}_{4}$ variations in combination with different MIR and NIR retrieval sensitivities. As the high mountain site Izaña is usually located above the planetary boundary layer (PBL), there should not be an impact on MIR and NIR retrievals. In contrast to that, Garmisch is located inside the PBL and therefore MIR and NIR retrievals are affected by this $\mathrm{CH}_{4}$ variability. For this reason, MIR and NIR retrievals at Izaña are expected to be in better agreement compared to Garmisch (and this is in line with our results), although retrievals affected by STE processes have been excluded for Garmisch.

Finally, the qualitative findings from the STE analysis of MIR and NIR retrievals at Garmisch can be transferred directly to the sites Karlsruhe, Wollongong, and Ny-Ålesund. As explained above, they are consistent with the site-specific characteristics at Izaña.

\section{Mitigation strategies for the stratospheric impact}

The stratospheric part of $\mathrm{CH}_{4}$ is defined by the position of the tropopause and the $\mathrm{CH}_{4} \mathrm{vmr}$ gradient in the UTLS. Whereas the $\mathrm{CH}_{4} \mathrm{vmr}$ gradient in the UTLS is the result of large-scale vertical transport (Brewer-Dobson circulation), the position of the tropopause depends on synoptic (e.g., polar vortex, STE) as well as seasonal variations (except for the tropics). Due to these facts the stratospheric part of $\mathrm{CH}_{4}$ can produce a lot of variability and uncertainty (smoothing effects) in the total column $\mathrm{CH}_{4}$ and, consequently, in $\mathrm{XCH}_{4}$. This variability can be misleading within the analysis of trends with regard to tropospheric emissions. Therefore, methods have been developed to overcome this problem of stratospheric variability by separating the tropospheric part of $\mathrm{CH}_{4}$ from the total column

First of all, Washenfelder et al. (2003) showed that stratospheric tracer-tracer relationships can be used to approximate the stratospheric $\mathrm{CH}_{4}$ in order to subtract it from the total column $\mathrm{CH}_{4}$ to get a tropospheric $\mathrm{CH}_{4}$ with a theoretical precision of $\sim 0.5 \%$. Their study was based on simultaneous NIR retrievals of $\mathrm{CH}_{4}$ and hydrogen fluoride (HF) that is strongly anticorrelated with stratospheric $\mathrm{CH}_{4}$. This method has been refined by Saad et al. (2014) by explicitly accounting for averaging kernels. As a result the mean precision of tropospheric $\mathrm{CH}_{4}$ was improved to $\sim 0.1 \%$. At the same time, Wang et al. (2014) showed that nitrous oxide $\left(\mathrm{N}_{2} \mathrm{O}\right)$ can also be an appropriate proxy for stratospheric $\mathrm{CH}_{4}$ with less $\mathrm{H}_{2} \mathrm{O}$ dependence compared to $\mathrm{HF}$. In contrast to NIR, the proxy retrieval is not applicable for MIR measurements, as shown by Sepúlveda et al. (2012). However, 
Table 4. As Table 2, but only for Garmisch using MIR and NIR retrievals which are coincident to the STE trajectory data set. Data sets are divided into monthly means using measurements from all days (Garmisch complete) or only days without STE events at Garmisch (Garmisch without STE).

\begin{tabular}{lllll}
\hline & & \multicolumn{2}{c}{ fit $y=b x$} \\
\cline { 3 - 5 } Data set & a priori & $\begin{array}{l}\text { slope } b \text { and } \\
2 \sigma \text { uncertainty }\end{array}$ & $\begin{array}{l}\text { slope different from } \\
1 \text { on } 2 \sigma \text { level? }\end{array}$ & SD (ppb) \\
\hline Garmisch complete & NIR \& MIR retrieved with original a priori & $1.0001(12)$ & no & 8.2 \\
Garmisch without STE & NIR \& MIR retrieved with original a priori & $1.0015(11)$ & yes & 6.5 \\
Garmisch complete & NIR \& MIR corrected to ACTM a priori & $0.9993(09)$ & no & 6.2 \\
Garmisch without STE & NIR \& MIR corrected to ACTM a priori & $1.0002(08)$ & no & 4.7 \\
\hline
\end{tabular}

the latter extracted tropospheric $\mathrm{CH}_{4}$ directly from optimized profile retrievals in the MIR.

Nevertheless, all methods mentioned have their limitations, e.g., Sepúlveda et al. (2014) found that their tropospheric $\mathrm{CH}_{4}$ product can be affected significantly by variations in the UTLS. They emphasize that tropospheric $\mathrm{CH}_{4}$ with a precision of $\sim 0.5 \%$ can be derived only by means of an a posteriori correction of the MIR retrievals. The results of the proxy methods in the NIR achieve high theoretical precision indeed, but their accuracy directly depends on the accuracy of the total column $\mathrm{CH}_{4}$ which is linked to the quality of a priori profiles. For example, especially in polar vortex conditions, NIR proxy retrievals are limited due to smoothing effects (Saad et al., 2014). In the end the smoothing effect described in Sect. 4.1.1 directly affects the accuracy of the tropospheric $\mathrm{CH}_{4}$ which points to the importance of realistic a priori profiles for scaling retrievals. One further problem is introduced by the complex structure of STE events because they do not only affect the stratosphere, but also the troposphere, as shown in Sect. 2.2.1.

Due to these reasons and the fact that our MIR retrieval strategy is optimized with regard to total columns, we decided to focus on total $\mathrm{XCH}_{4}$. However, a comparison of tropospheric NIR and MIR retrievals is certainly interesting. It is obvious that such an intercomparison should be performed with retrieval methods dedicated to tropospheric columns, and improved a priori profiles that are able to reproduce the polar vortex subsidence in a realistic way. The NIR proxy retrievals (Saad et al., 2014; Wang et al., 2014) will benefit from these a priori profiles in the same way as the total column retrievals. In addition to that, these profiles could be used by tropospheric MIR profile retrievals (Sepúlveda et al., 2014), thereby acting as a common prior within an intercomparison study.

Attention should also be paid to the dependence of $\mathrm{XCH}_{4}$ on stratospheric variability with regard to validation of satellite and model data. This means that the prior and the averaging kernels should be taken into account, particularly as satellites have their own vertical sensitivities. In the case of similar vertical sensitivities we can assume that the smoothing effects from satellite and ground-based retrievals are of nearly equal magnitude. Hence, remaining differences can be attributed to other error sources such as systematic errors. Thus, NIR TCCON retrievals may be more valuable than MIR NDACC retrievals if SWIR (shortwave infrared) sounders such as GOSAT or SCIAMACHY are concerned. Furthermore, it is important to be very careful with the interpretation of results when evaluating model data from arctic regions.

Instead of separating the stratospheric part from the total column, we tried to detect and exclude situations with high dynamical variability by analyzing meteorological parameters (Sects. 4.1.2 and 4.2.2). In future, these meteorological criteria for exclusion could be installed as additional information in the prior data (TCCON). Another possibility for the exclusion of affected data has been presented by Angelbratt et al. (2011). They used a multiple regression model with anomalies of HF, carbon monoxide (CO), and tropopause height to reduce the variability in total column $\mathrm{CH}_{4}$. This concept of anomalies can also be transferred to the retrieval process. Certain threshold values of stratospheric tracers $\left(\mathrm{HF}, \mathrm{N}_{2} \mathrm{O}\right.$ ) can be implemented as filter criteria for $\mathrm{XCH}_{4}$. In Appendix D we show that HF is suitable for detecting polar vortex subsidence. In contrast, the situation with STE is much more complex and HF cannot be recommended as an additional filter criterion.

Substantial progress could be achieved when combining the NIR and MIR measurements in a concurrent retrieval setup. In this approach the difference in averaging kernels is not considered as a problem but as an opportunity to differentiate more atmospheric layers. The synergetic potential of such an approach seems to be more promising in the case of polar vortex subsidence because the dynamics of subsidence are not as fine-structured compared to STE events. However, the main objective of combining both retrievals will be to determine the shape of the stratospheric $\mathrm{CH}_{4}$ profile. Hence, reducing the uncertainty of the stratospheric $\mathrm{CH}_{4}$ will be beneficial for models and retrievals. We want to construct such a combined method and also want to present the method in a subsequent study. 


\section{Summary and conclusions}

We have compared MIR (NDACC) and NIR (TCCON) retrievals of $\mathrm{XCH}_{4}$ obtained at the sites Garmisch, Karlsruhe, Izaña, Wollongong, and Ny-Ålesund. Our intercomparison results (Table 2) confirm the major findings from Sussmann et al. (2013). That is, there is no need to apply an MIR/NIR intercalibration factor due to very good overall agreement of the original MIR and NIR data sets as retrieved (except NyAllesund). Furthermore, we showed that the remaining seasonal bias could be reduced by using a realistic site-specific and time-dependent common prior (ACTM). However, residual differences in Sussmann et al. (2013) and also in the present study reached significant levels (up to $\sim 30 \mathrm{ppb}$ for Ny-Ålesund), limiting the accuracy of the MIR and NIR seasonal cycles.

In this paper we were able to show that dynamical variability is the main source for these residual differences. Thereby, we complement the outcomes from Sussmann et al. (2013) with important additional findings about the characteristics of MIR and NIR retrievals of methane.

In extreme scenarios of atmospheric variability, i.e., stratospheric subsidence or deep STE events, the approach using a common model prior to reducing differing smoothing errors fails because the model profile is likely to deviate from the true atmospheric $\mathrm{CH}_{4}$ profile. By means of a case study we showed that stratospheric subsidence at Ny-Ålesund is associated with large differences between MIR and NIR retrievals $(\sim 29 \mathrm{ppb}$ for the time period 08:00-10:00 UT on 25 March 2011). Another case study indicated that a deep stratospheric intrusion at Garmisch gives rise to residual differences of up to $\sim 15 \mathrm{ppb}$. Due to the different vertical sensitivities (averaging kernels), the smoothing effects of MIR and NIR retrievals are unequal for both case studies. While NIR retrievals are affected by stratospheric subsidence more than MIR retrievals, the situation is reversed for STE processes such as deep stratospheric intrusions. As a consequence, both the exclusion of Ny-Ålesund retrievals affected by stratospheric subsidence and the exclusion of Garmisch retrievals affected by STE processes resulted in improved agreement of MIR and NIR seasonal cycles (Tables 3, 4).

We found that $23 \%$ of the FTIR measurement days at Ny-Ålesund are influenced by the polar vortex and $35 \%$ of the FTIR measurement days at Garmisch are influenced by STE. Considering that the high increase in $\mathrm{XCH}_{4}$ of $\sim 25 \mathrm{ppb}$ within $1 \mathrm{~h}$ at Garmisch is related to a deep stratospheric intrusion, it is obvious that such STE processes are able to introduce a remarkable variation in $\mathrm{XCH}_{4}$. From the geographical and seasonal variability of STE presented in Sprenger and Wernli (2003) we conclude that, in contrast to Izaña, the other midlatitude sites (Karlsruhe, Wollongong) and the polar site (Ny-Ålesund) are also affected by STE processes. This is in line with the very good agreement of the MIR and NIR seasonal cycles for Izaña.
We conclude that atmospheric variability (subsidence, STE, and stratospheric variability in general) is a key factor in constraining the accuracy of MIR and NIR seasonal cycles. Different vertical sensitivities for both retrievals give rise to different smoothing effects. We showed that this impact can be mitigated by means of two basically different approaches. Either situations with high atmospheric variability are detected and excluded from further analysis or one has to focus on retrievals of tropospheric $\mathrm{XCH}_{4}$ (Sect. 5). Nevertheless, NIR and MIR $\mathrm{XCH}_{4}$ retrievals can be used in inversions without limitation of data. For example, inversions can explicitly account for averaging kernels and a priori profiles, thereby reducing the bias between MIR and NIR. At the same time, both measurements will be consistent with the model. In addition to that, inverse models are able to take the smoothing error directly into account.

One step forward would be to use models as a transfer standard between MIR and NIR column retrievals. Assuming that only the true $\mathrm{CH}_{4}$ profile is able to harmonize NDACC and TCCON retrievals of $\mathrm{XCH}_{4}$, it is possible to construct a concurrent retrieval setup. The synergetic potential of such a combined method is based on the different vertical sensitivities of the retrievals. A study on this subject has already been initiated and is subject of a subsequent publication.

However, NIR retrievals at polar sites may be improved by accounting for stratospheric subsidence in the standard retrieval a priori. Improving the quality of MIR retrievals affected by STE seems to be more complicated due to the diversity of STE processes. However, we conjecture that more realistic a priori profiles from high-resolution models reflecting small-scale processes could help to reduce MIR smoothing effects. An alternative method to overcome this problem would be to further improve the FTIR retrievals with the target to achieve a more uniform sensitivity at all altitudes; i.e., if the MIR averaging kernel was more evenly weighted with altitude then the MIR dependence on STE should be reduced. Also, using a formal optimal estimation (OE) inverse technique in GFIT could foreseeably help to improve the sensitivity of NIR retrievals to subsidence.

When using NDACC and/or TCCON XCH 4 data, it is critical to be aware of the effects of dynamic events on the accuracy of the relevant data set. Depending on the requirements on data accuracy, NDACC and/or TCCON $\mathrm{XCH}_{4}$ data can be used with or without the exclusion of dynamical events. Methods to detect these events have been presented in this study. Given a proper data use based on the findings in this paper, a joint NDACC and TCCON data set will result in wider spatial and longer temporal coverage of $\mathrm{XCH}_{4}$ data for the validation of top-down estimates, satellite validation, and trend studies. 


\section{Appendix A: Description of FTIR sounding sites}

\section{A1 Garmisch}

The Garmisch solar FTIR system $\left(47.48^{\circ} \mathrm{N}, 11.06^{\circ} \mathrm{E}\right.$, $743 \mathrm{~m}$ a.s.1.) is operated by the group Atmospheric Variability and Trends at the Institute of Meteorology and Climate Research - Atmospheric Environmental Research (IMKIFU), Karlsruhe Institute of Technology (KIT). Columnaveraged methane is retrieved from FTIR measurements performed with a Bruker IFS125HR interferometer. NIR forward and backward single-scan measurements are recorded with an InGaAs detector by using a maximum optical path difference of $45 \mathrm{~cm}$. In the MIR spectral range the solar absorption spectra are detected with an InSb detector using a maximum optical path difference of $175 \mathrm{~cm}$ and averaging six scans with an integration time of approximately $7 \mathrm{~min}$.

The Garmisch FTIR system took part in the aircraft calibration campaign of the EU project IMECC (Infrastructure for Measurement of the European Carbon Cycle) (Messerschmidt et al., 2011; Geibel et al., 2012). Garmisch FTIR measurements have been used for satellite validation (de Laat et al., 2010; Morino et al., 2011; Wunch et al., 2011b), carbon cycle research (Chevallier et al., 2011), and studies of atmospheric variability and trends (e.g., Borsdorff and Sussmann, 2009; Sussmann et al., 2009, 2012). The intercalibration of MIR and NIR measurements in this study covers the time period from July 2007 to December 2012.

\section{A2 Wollongong}

The Wollongong solar FTIR system $\left(34.41^{\circ} \mathrm{S}, 150.88^{\circ} \mathrm{E}\right.$, $30 \mathrm{~m}$ a.s.l.) is operated by the Centre for Atmospheric Chemistry at the University of Wollongong, Australia. The intercomparison uses the Wollongong time series of June 2008December 2012. In this time period the FTIR measurements were performed with a Bruker IFS125HR instrument. The settings for NIR measurements are identical to those at Garmisch. In the MIR spectral range solar absorption spectra were recorded with an InSb detector, using an optical path difference of $257 \mathrm{~cm}$ and averaging two scans with an integration time of approximately 4 min. Data obtained from Wollongong FTIR have contributed to a chemical-transport model validation by using MIR measurements of stratospheric tracer total column abundances (Kohlhepp et al., 2012).

\section{A3 Karlsruhe}

The Karlsruhe solar FTIR system $\left(49.08^{\circ} \mathrm{N}, 8.43^{\circ} \mathrm{E}\right.$, $110 \mathrm{~m}$ a.s.l.) is operated by the group Ground-based remotesensing at the Institute for Meteorology and Climate Research - Atmospheric Trace Gases (IMK-ASF), KIT, Germany. In 2009 a new FTIR container with a Bruker IFS125HR interferometer was set up for solar absorption measurements in the MIR and NIR.
The settings for NIR measurements are identical to those at Garmisch. MIR measurements are performed with an InSb detector using a maximum optical path difference of $180 \mathrm{~cm}$. Four scans are averaged with an integration time of $9.5 \mathrm{~min}$. This study uses MIR and NIR measurements out of the time period from March 2010 to December 2012. The Karlsruhe FTIR system participated in the aircraft calibration campaign of the EU project IMECC.

\section{A4 Izaña}

The Izaña solar FTIR system $\left(28.31^{\circ} \mathrm{N}, 16.45^{\circ} \mathrm{W}\right.$, $2370 \mathrm{~m}$ a.s.l.) is located on the Canary Island of Tenerife and is part of a collaboration between the Meteorological State Agency of Spain (Spanish acronym: AEMET) and KIT. It is operated by the Izaña Atmospheric Research Center and the responsibility for the FTIR experiment lies with IMK-ASF of the Karlsruhe Institute for Technology.

Because measurements from 2007 to 2010 are affected by laser sampling ghosts, the intercalibration only uses FTIR data from December 2010 to December 2012 which have been recorded with a Bruker IFS125HR interferometer. The settings for NIR measurements are identical to those at Karlsruhe. The interferograms for the MIR retrievals are operated with an InSb detector using a maximum optical path difference of $180 \mathrm{~cm}$ before averaging six scans with an integration time of about 7 min. Izaña FTIR measurements have been used for a long-term validation of tropospheric column-averaged methane in the midinfrared spectral region (Sepúlveda et al., 2012) and have also been part of a technical study about a method for ghost correction in historic near-infrared FTIR measurements (Dohe et al., 2013).

\section{A5 Ny-Ålesund}

The Ny-Ålesund solar FTIR system $\left(78.92^{\circ} \mathrm{N}, 11.93^{\circ} \mathrm{E}\right.$, $20 \mathrm{~m}$ a.s.l.) is part of the the joint French-German Arctic Research Base AWIPEV (Alfred Wegener Institute for Polar and Marine Research and the French Polar Institute Paul Emile Victor) on the Svalbard archipelago. The intercalibration contains FTIR measurements from March 2005 to $\mathrm{Au}-$ gust 2012 which have been performed with a Bruker 120HR interferometer by the AWI (Alfred Wegener Institute) Potsdam and the University of Bremen. Ground-based solar absorption measurements are operated from the end of March until the end of September when the polar night begins.

Column-averaged methane is retrieved from double-scan TCCON-type measurements recorded with an InGaAs diode using a maximum optical path difference of $30 \mathrm{~cm}$. No DC/solar intensity variation correction was applied to $\mathrm{Ny}-$ Ålesund data. MIR retrievals are recorded with an InSb detector by using an optical path difference of $180 \mathrm{~cm}$. Two scans are averaged with an integration time of approximately $2.5 \mathrm{~min}$. 
Appendix B: Derivation of a typical strongly subsided $\mathrm{CH}_{4}$ profile for $\mathrm{Ny}$-Ålesund

Inside the polar vortex, stratospheric subsidence leads to a depletion of the total columns of tropospheric source gases, whereas outside the polar vortex the columns of these gases remain unchanged. Based on the assumption that this variation of total columns is the result of vertical transport alone, Toon at al. (1992b) derived a mapping transformation which links points on the vmr profile outside the vortex to the same vmr inside according to the relation

$\operatorname{vmr}_{\text {subsided }}(z)=\operatorname{vmr}(z(1+$ DOS $))$,

where DOS is the degree of subsidence.

As explained in Sect. 4.1.1, Ny-Ålesund was affected by strong subsidence on 25 March 2011. Therefore, we decided to use a typical maximum DOS value of 0.44 to account for subsidence in the MIR and NIR retrievals on 25 March 2011. Equation (B1) was applied to the MIR original a priori profile (from WACCM) above the tropopause to get a subsided common prior (see Fig. 3a, MIR a priori subsided $_{\text {) }}$. 


\section{Appendix C: Supplementary figures}

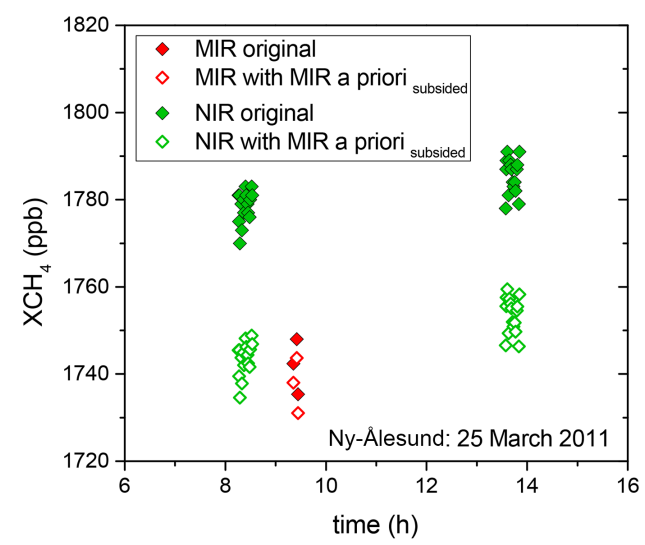

Figure C1. Same as Fig. 4 but MIR and NIR retrievals as computed with their standard (original) retrieval a priori profiles (filled squares) and as corrected to a strongly subsided MIR a priori profile (open squares) as shown in Fig. 3a.
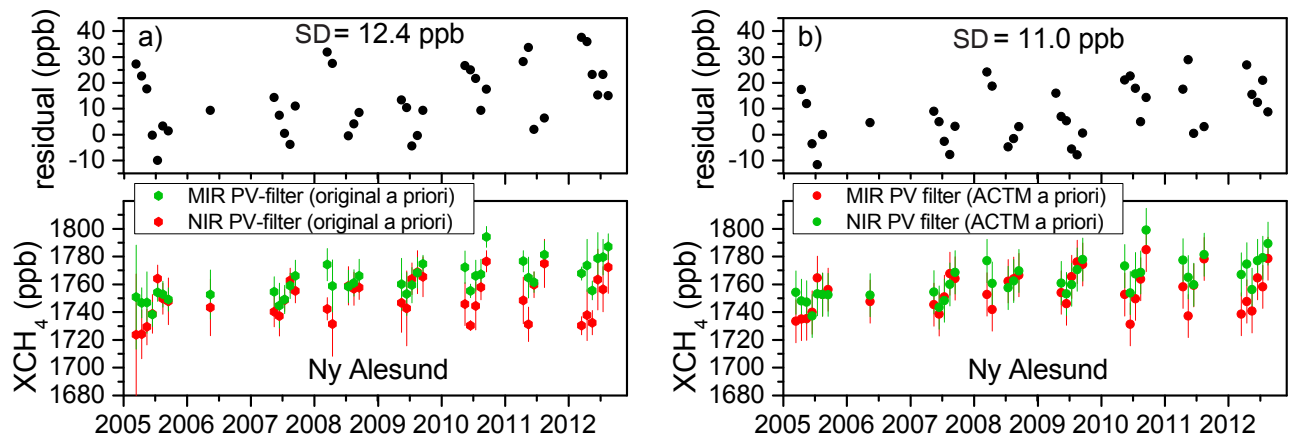

Figure C2. Same as Fig. 2 for Ny-Ålesund but excluding retrievals affected from stratospheric subsidence via PV as an extra filter criterion (see Sect. 4.1.2). (a) NIR and MIR retrievals with their original standard retrieval a priori profiles. (b) NIR and MIR retrievals corrected to the common ACTM a priori profile.
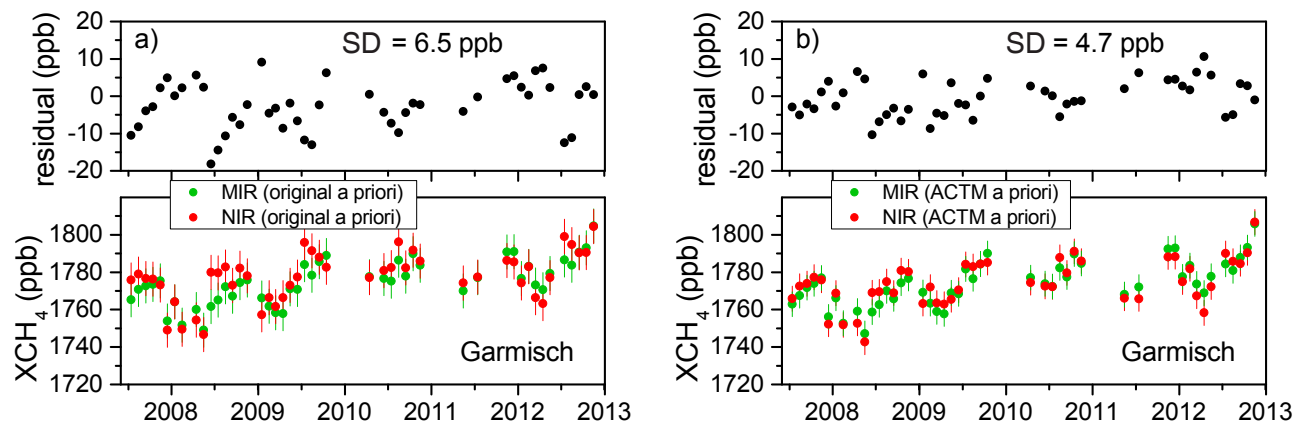

Figure C3. Same as Fig. 2 for Garmisch but excluding retrievals affected from STE events (see Sect. 4.2.2). (a) NIR and MIR retrievals with their original standard retrieval a priori profile. (b) NIR and MIR retrievals corrected to the common ACTM a priori profile. 


\section{Appendix D: Supplementary figures}

In Sects. 4.1.2 and 4.2.2 we applied meteorological criteria for detecting situations with polar vortex subsidence, and STE, respectively. These methods are complex and not really practicable in the operational retrieval process. In contrast to that, it seems to be logical to use simultaneous measurements of stratospheric tracers $\left(\mathrm{HF}, \mathrm{N}_{2} \mathrm{O}\right)$ for detecting polar vortex subsidence and STE. The chemically inert trace gas HF appears to be an excellent candidate for such an intention since it is strongly anticorrelated with stratospheric $\mathrm{CH}_{4}$.

In the case of polar vortex subsidence it can be expected that the stratospheric $\mathrm{CH}_{4}$ depletion involves an enhancement in the HF total column. Figure D1 shows the NIR XHF daily mean time series of $\mathrm{Ny}-\AA \AA^{2}$ lesund. Measurement days with polar vortex subsidence were identified in Sect. 4.1.2 and are highlighted in Fig. D1. Indeed, it is clearly recognizable that the XHF values are significantly higher $(\sim$ factor 2$)$ at the predominant part of polar vortex situations. Therefore, we conclude that it would be possible to exclude polar vortex situations at Ny-Ålesund with an XHF threshold of $\sim 100 \mathrm{ppt}$ (parts per trillion).

In contrast to that, the situation is more difficult with regard to STE due to its complex nature. Thus, it is possible that both enhancements and depletions of $\mathrm{CH}_{4}$ and consequently HF can occur. Figure D2 shows the NIR XHF daily mean time series of Garmisch. Days with and without STE were identified according to Sect. 4.2.2 and can be distinguished in Fig. D2. It is obvious that XHF is in same range of values in situations with STE as in situations without STE. Hence, XHF is not suitable for the detection of STE events.

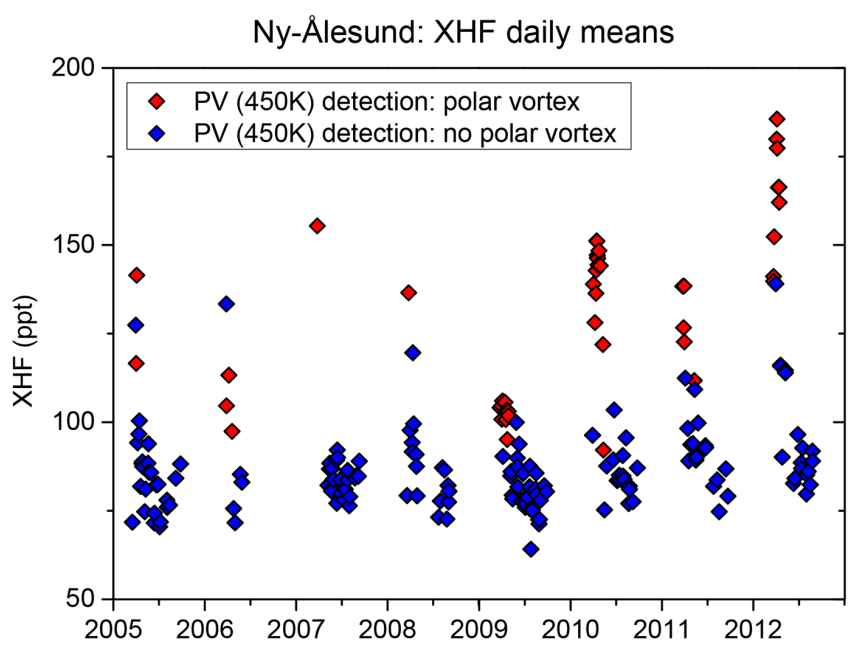

Figure D1. XHF daily mean time series for Ny-Ålesund obtained from NIR measurements (TCCON). Polar vortex days were detected by using the PV criterion by Nash et al. (1996).

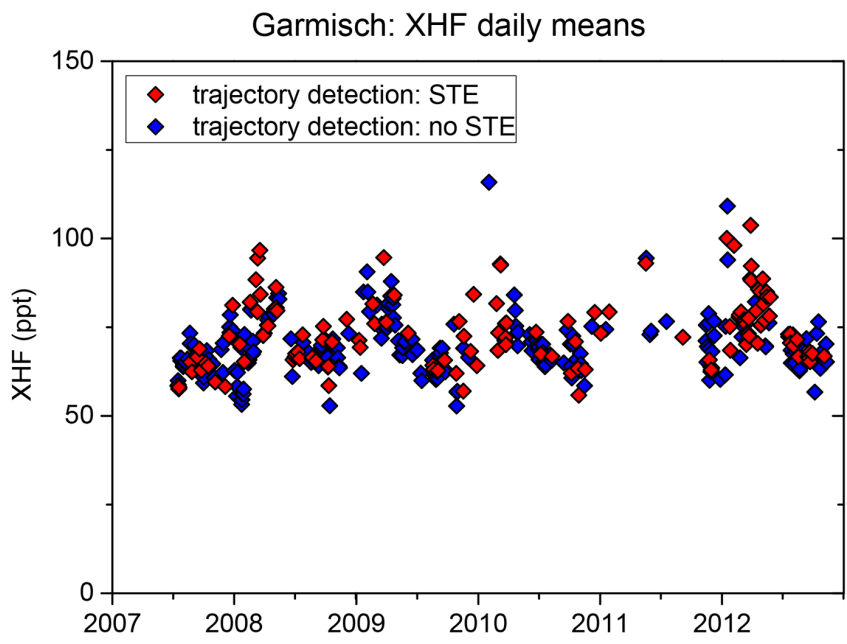

Figure D2. XHF daily mean time series for Garmisch obtained from NIR measurements (TCCON). The detection of measurement days affected by STE is described in Sect. 4.2.2. 
Acknowledgements. We are indebted to P. K. Patra (JAMSTEC) for providing ACTM model data and thank T. Blumenstock (KIT) and O. E. García-Rodríguez (AEMET) for making Izaña FTIR data available. Furthermore, we thank D. W. T. Griffith (University of Wollongong) and J. Notholt (IUP) for providing FTIR data from Wollongong and Ny-Ålesund, respectively. We thank H. P. Schmid (IMK-IFU) for his continual interest in this work. Provision of the GFIT code by G. Toon (JPL) is gratefully acknowledged. Our work has been performed as part of the ESA GHG-cci project via subcontract with the University of Bremen. In addition we acknowledge funding by the EC within the INGOS project. We thank the ECMWF for providing access to the meteorological data. We thank the Deutsche Forschungsgemeinschaft and Open Access Publishing Fund of the Karlsruhe Institute of Technology for support. The Wollongong work was funded through the Australian International Science Linkage grant CG130014 and the Australian Research Council, grants DP0879468 and DP110103118.

The service charges for this open access publication

have been covered by a Research Centre of the

Helmholtz Association.

Edited by: J. Joiner

\section{References}

Angelbratt, J., Mellqvist, J., Blumenstock, T., Borsdorff, T., Brohede, S., Duchatelet, P., Forster, F., Hase, F., Mahieu, E., Murtagh, D., Petersen, A. K., Schneider, M., Sussmann, R., and Urban, J.: A new method to detect long term trends of methane $\left(\mathrm{CH}_{4}\right)$ and nitrous oxide $\left(\mathrm{N}_{2} \mathrm{O}\right)$ total columns measured within the NDACC ground-based high resolution solar FTIR network, Atmos. Chem. Phys., 11, 6167-6183, doi:10.5194/acp-11-61672011, 2011.

Allan, W., Struthers, H., and Lowe, D. C.: Methane carbon isotope effects caused by atomic chlorine in the marine boundary layer: Global model results compared with Southern Hemisphere measurements, J. Geophys. Res., 112, D04306, doi:10.1029/2006JD007369, 2007.

Archer, D.: Methane hydrate stability and anthropogenic climate change, Global Biogeochem. Cy., 4, 521-544, doi:10.5194/bg4-521-2007, 2007.

Belikov, D., Maksyutov, S., Miyasaka, T., Saeki, T., Zhuravlev, R., and Kiryushov, B.: Mass-conserving tracer transport modelling on a reduced latitude-longitude grid with NIES-TM, Geosci. Model Dev., 4, 207-222, doi:10.5194/gmd-4-207-2011, 2011.

Bergamaschi, P., Frankenberg, C., Meirink, J. F., Krol, M., Villani, M. G., Houweling, S., Dentener, F., Dlugokencky, E. J., Miller, J. B., Gatti, L. V., Engel, A., and Levin, I.: Inverse modeling of global and regional $\mathrm{CH}_{4}$ emissions using SCIAMACHY satellite retrievals, J. Geophys. Res., 114, D22301, doi:10.1029/2009JD012287, 2009.

Bergamaschi, P., Houweling, S., Segers, A., Krol, M., Frankenberg, C., Scheepmaker, R. A., Dlugokencky, E., Wofsy, S. C., Kort, E. A., Sweeney, C., Schuck, T., Brenninkmeijer, C., Chen, H., Beck, V., and Gerbig, C.: Atmospheric $\mathrm{CH}_{4}$ in the first decade of the 21 st century: inverse modeling analysis using SCIAMACHY satellite retrievals and NOAA surface measurements, J. Geophys Res., 118, 7350-7369, doi:10.1002/jgrd.50480, 2013.

Borsdorff, T. and Sussmann, R.: On seasonality of stratomesospheric $\mathrm{CO}$ above midlatitudes: New insight from solar FTIR spectrometry at Zugspitze and Garmisch, Geophys. Res. Lett., 36, L21804, doi:10.1029/2009GL040056, 2009.

Bousquet, P., Ciais, P., Miller, J. B., Dlugokencky, E. J., Hauglustaine, D. A., Prigent, C., Van der Werf, G. R., Peylin, P., Brunke, E. G., Carouge, C., Langenfels, R. L., Lathiere, J., Papa, F., Ramonet, M., Schmidt, M., Steele, L. P., Tyler, S. C., and White, J.: Contribution of anthropogenic and natural sources to atmospheric methane variability, Nature, 443, 439-443, 2006.

Bousquet, P., Ringeval, B., Pison, I., Dlugokencky, E. J., Brunke, E.G., Carouge, C., Chevallier, F., Fortems-Cheiney, A., Frankenberg, C., Hauglustaine, D. A., Krummel, P. B., Langenfelds, R. L., Ramonet, M., Schmidt, M., Steele, L. P., Szopa, S., Yver, C., Viovy, N., and Ciais, P.: Source attribution of the changes in atmospheric methane for 2006-2008, Atmos. Chem. Phys., 11, 3689-3700, doi:10.5194/acp-11-3689-2011, 2011.

Butz, A., Guerlet, S., Hasekamp, O., Schepers, D., Galli, A., Aben, I., Frankenberg, C., Hartmann, J. M., Tran, H., Kuze, A., Keppel-Aleks, G., Toon, G., Wunch, D., Wennberg, P., Deutscher, N., Griffith, D., Macatangay, R., Messerschmidt, J., Notholt, J., and Warneke, T.: Toward accurate $\mathrm{CO}_{2}$ and $\mathrm{CH}_{4}$ observations from GOSAT, Geophys. Res. Lett., 38, L14812, doi:10.1029/2011GL047888, 2011.

Chevallier, F., Deutscher, N., Conway, C. J., Ciais, P., Ciattaglia, L., Dohe, S., Fröhlich, M., Gomez-Pelaez, A.J., Griffith, D., Hase, F., Haszpra, L., Krummel, P., Kyrö, E., Labuschagne, C., Langenfelds, R., Machida, T., Maignan, F., Matsueda, H., Morino, I., Notholt, J., Ramonet, M., Sawa, Y., Schmidt, M., Sherlock, V., Steele, P., Strong, K., Sussmann, R., Wennberg, P., Wofsy, S., Worthy, D., Wunch, D., and Zimnoch, M.: Global $\mathrm{CO}_{2}$ surface fluxes inferred from surface air-sample measurements and from surface retrievals of the $\mathrm{CO}_{2}$ total column, Geophys. Res. Lett., 38, L24810, doi:10.1029/2011GL049899, 2011.

Cicerone, R. J. and Oremland, R. S.: Biogeochemical aspects of atmospheric methane, Global Biogeochem. Cy., 2, 299-327, doi:10.1029/GB002i004p00299, 1988.

de Laat, A. T. J., Gloudemans, A. M. S., Schrijver, H., Aben, I., Nagahama, Y., Suzuki, K., Mahieu, E., Jones, N. B., Paton-Walsh, C., Deutscher, N. M., Griffith, D. W. T., De Mazière, M., Mittermeier, R. L., Fast, H., Notholt, J., Palm, M., Hawat, T., Blumenstock, T., Hase, F., Schneider, M., Rinsland, C., Dzhola, A. V., Grechko, E. I., Poberovskii, A. M., Makarova, M. V., Mellqvist, J., Strandberg, A., Sussmann, R., Borsdorff, T., and Rettinger, M.: Validation of five years (2003-2007) of SCIAMACHY CO total column measurements using ground-based spectrometer observations, Atmos. Meas. Tech., 3, 1457-1471, doi:10.5194/amt3-1457-2010, 2010.

De Mazière, M., Vigouroux, C., Bernath, P. F., Baron, P., Blumenstock, T., Boone, C., Brogniez, C., Catoire, V., Coffey, M., Duchatelet, P., Griffith, D., Hannigan, J., Kasai, Y., Kramer, I., Jones, N., Mahieu, E., Manney, G. L., Piccolo, C., Randall, C., Robert, C., Senten, C., Strong, K., Taylor, J., Tétard, C., Walker, K. A., and Wood, S.: Validation of ACE-FTS v2.2 methane profiles from the upper troposphere to the lower mesosphere, Atmos. Chem. Phys., 8, 2421-2435, doi:10.5194/acp-8-2421-2008, 2008. 
Dlugokencky, E. J., Nisbet E. G., Fisher R., and Lowry, D.: Global atmospheric methane: budget, changes and dangers, Phil. Trans. R. Soc. A, 369, 2058-2072, doi:10.1098/rsta.2010.0341, 2011.

Dohe, S., Sherlock, V., Hase, F., Gisi, M., Robinson, J., Sepúlveda, E., Schneider, M., and Blumenstock, T.: A method to correct sampling ghosts in historic near-infrared Fourier transform spectrometer (FTS) measurements, Atmos. Meas. Tech., 6, 19811992, doi:10.5194/amt-6-1981-2013, 2013.

Frankenberg, C., Warneke, T., Butz, A., Aben, I., Hase, F., Spietz, P., and Brown, L. R.: Pressure broadening in the $2 v_{3}$ band of methane and its implication on atmospheric retrievals, Atmos. Chem. Phys., 8, 5061-5075, doi:10.5194/acp-8-5061-2008, 2008.

Fraser, A., Palmer, P. I., Feng, L., Boesch, H., Cogan, A., Parker, R., Dlugokencky, E. J., Fraser, P. J., Krummel, P. B., Langenfelds, R. L., O'Doherty, S., Prinn, R. G., Steele, L. P., van der Schoot, M., and Weiss, R. F.: Estimating regional methane surface fluxes: the relative importance of surface and GOSAT mole fraction measurements, Atmos. Chem. Phys., 13, 5697-5713, doi:10.5194/acp-13-5697-2013, 2013.

Garcia, R. R., Marsh, D. R., Kinnison, D. E., Boville, B. A., and Sassi, F.: Simulation of secular trends in the middle atmosphere, 1950-2003, J. Geophys. Res., 112, D09301, doi:10.1029/2006JD007485, 2007.

Geibel, M. C., Messerschmidt, J., Gerbig, C., Blumenstock, T., Chen, H., Hase, F., Kolle, O., Lavrič, J. V., Notholt, J., Palm, M., Rettinger, M., Schmidt, M., Sussmann, R., Warneke, T., and Feist, D. G.: Calibration of column-averaged $\mathrm{CH}_{4}$ over European TCCON FTS sites with airborne in-situ measurements, Atmos. Chem. Phys., 12, 8763-8775, doi:10.5194/acp-12-87632012, 2012.

Hase, F., Hannigan, J. W., Coffey, M. T., Goldman, A., Höpfner, M., Jones, N. B., Rinsland, C. P., and Wood, S. W.: Intercomparison of retrieval codes used for the analysis of high-resolution, ground-based FTIR measurements, J. Quant. Spectrosc. Radiat. Transfer, 87, 25-52, 2004.

Houweling, S., van der Werf, G. R., Goldewijk, K. K., Roeckmann, T., and Aben, I.: Early anthropogenic $\mathrm{CH}_{4}$ emissions and the variation of $\mathrm{CH}_{4}$ and ${ }^{13} \mathrm{CH}_{4}$ over the last millennium, Global Biogeochem. Cy., 22, GB1002, doi:10.1029/2007GB002961, 2008.

Houweling, S., Aben, I., Breon, F.-M., Chevallier, F., Deutscher, N., Engelen, R., Gerbig, C., Griffith, D., Hungershoefer, K., Macatangay, R., Marshall, J., Notholt, J., Peters, W., and Serrar, S.: The importance of transport model uncertainties for the estimation of $\mathrm{CO}_{2}$ sources and sinks using satellite measurements, Atmos. Chem. Phys., 10, 9981-9992, doi:10.5194/acp-10-99812010, 2010.

Houweling, S., Krol, M., Bergamaschi, P., Frankenberg, C., Dlugokencky, E. J., Morino, I., Notholt, J., Sherlock, V., Wunch, D., Beck, V., Gerbig, C., Chen, H., Kort, E. A., Röckmann, T., and Aben, I.: A multi-year methane inversion using SCIAMACHY, accounting for systematic errors using TCCON measurements, Atmos. Chem. Phys., 14, 3991-4012, doi:10.5194/acp-14-39912014, 2014.

Kirschke, S., Bousquet, P., Ciais, P., Saunois, M., Canadell, J. G., Dlugokencky, E. J., Bergamaschi, P., Bergmann, D., Blake, D. R., Bruhwiler, L., Cameron-Smith, P., Castaldi, S., Chevallier, F., Feng, L., Fraser, A., Heimann, M., Hodson, E. L., Houwel- ing, S., Josse, B., Fraser, P. J., Krummel, P. B., Lamarque, J. F., Langenfelds, R. L., Le Quere, C., Naik, V., O’Doherty, S., Palmer, P. I., Pison, I., Plummer, D., Poulter, B., Prinn, R. G., Rigby, M., Ringeval, B., Santini, M., Schmidt, M., Shindell, D. T., Simpson, I., Spahni, R., Steele, L. P., Strode, S. A., Sudo, K., Szopa, S., van der Werf, G. R., Voulgarakis, A., van Weele, M., Weiss, R. F., Williams, J. E., and Zeng, G.: Three decades of global methane sources and sinks, Nat. Geosci., 6, 813-823, doi:10.1038/ngeo1955, 2013.

Kohlhepp, R., Ruhnke, R., Chipperfield, M. P., De Mazière, M., Notholt, J., Barthlott, S., Batchelor, R. L., Blatherwick, R. D., Blumenstock, Th., Coffey, M. T., Demoulin, P., Fast, H., Feng, W., Goldman, A., Griffith, D. W. T., Hamann, K., Hannigan, J. W., Hase, F., Jones, N. B., Kagawa, A., Kaiser, I., Kasai, Y., Kirner, O., Kouker, W., Lindenmaier, R., Mahieu, E., Mittermeier, R. L., Monge-Sanz, B., Morino, I., Murata, I., Nakajima, H., Palm, M., Paton-Walsh, C., Raffalski, U., Reddmann, Th., Rettinger, M., Rinsland, C. P., Rozanov, E., Schneider, M., Senten, C., Servais, C., Sinnhuber, B.-M., Smale, D., Strong, K., Sussmann, R., Taylor, J. R., Vanhaelewyn, G., Warneke, T., Whaley, C., Wiehle, M., and Wood, S. W.: Observed and simulated time evolution of $\mathrm{HCl}, \mathrm{ClONO}_{2}$, and $\mathrm{HF}$ total column abundances, Atmos. Chem. Phys., 12, 3527-3556, doi:10.5194/acp12-3527-2012, 2012.

Lin, M., Fiore, A. M., Cooper, O. R., Horowitz, L. W., Langford, A. O., Levy II, H., Johnson, B. J., Naik, V., Oltmans, S. J., and Senff, C. J.: Springtime high surface ozone events over the western United States: Quantifying the role of stratospheric intrusions, J. Geophys. Res., 117, D00V22, doi:10.1029/2012JD018151, 2012.

Lindenmaier, R., Strong, K., Batchelor, R. L., Chipperfield, M. P., Daffer, W. H., Drummond, J. R., Duck, T. J., Fast, H., Feng, W., Fogal, P. F., Kolonjari, F., Manney, G. L., Manson, A., Meek, C., Mittermeier, R. L., Nott, G. J., Perro, C., and Walker, K. A.: Unusually low ozone, $\mathrm{HCl}$, and $\mathrm{HNO}_{3}$ column measurements at Eureka, Canada during winter/spring 2011, Atmos. Chem. Phys., 12, 3821-3835, doi:10.5194/acp-12-3821-2012, 2012.

Messerschmidt, J., Geibel, M. C., Blumenstock, T., Chen, H., Deutscher, N. M., Engel, A., Feist, D. G., Gerbig, C., Gisi, M., Hase, F., Katrynski, K., Kolle, O., Lavrič, J. V., Notholt, J., Palm, M., Ramonet, M., Rettinger, M., Schmidt, M., Sussmann, R., Toon, G. C., Truong, F., Warneke, T., Wennberg, P. O., Wunch, D., and Xueref-Remy, I.: Calibration of TCCON column-averaged $\mathrm{CO} 2$ : the first aircraft campaign over European TCCON sites, Atmos. Chem. Phys., 11, 10765-10777, doi:10.5194/acp-11-10765-2011, 2011.

Monteil, G., Houweling, S., Butz, A., Guerlet, S., Schepers, D., Hasekamp, O., Frankenberg, C., Scheepmaker, R., Aben, I., and Röckmann, T.: Comparison of $\mathrm{CH}_{4}$ inversions based on 15 months of GOSAT and SCIAMACHY observations, J. Geophys. Res. Atmos., 118, 11807-11823, doi:10.1002/2013JD019760, 2013.

Morino, I., Uchino, O., Inoue, M., Yoshida, Y., Yokota, T., Wennberg, P. O., Toon, G. C., Wunch, D., Roehl, C. M., Notholt, J., Warneke, T., Messerschmidt, J., Griffith, D. W. T., Deutscher, N. M., Sherlock, V., Connor, B., Robinson, J., Sussmann, R., and Rettinger, M.: Preliminary validation of column-averaged volume mixing ratios of carbon dioxide and methane retrieved from 
GOSAT short-wavelength infrared spectra, Atmos. Meas. Tech., 4, 1061-1076, doi:10.5194/amt-4-1061-2011, 2011.

Nash, E. R., Newman, P. A., Rosenfield, J. E., and Schoeberl, M. R.: An objective determination of the polar vortex using Ertel's potential vorticity, J. Geophys. Res., 101, 9471-9478, 1996.

Patra, P. K., Takigawa, M., Ishijima, K., Choi, B.-C., Cunnold, D., Dlugokencky, E. J., Fraser, P., Gomez-Pelaez, A. J., Goo, T.-Y., Kim, J.-S., Krummel, P., Langenfelds, R., Meinhardt, F., Mukai, H., O’Doherty, S., Prinn, R. G., Simmonds, P., Steele, P., Tohjima, Y., Tsuboi, K., Uhse, K., Weiss, R., Worthy, D., and Nakazawa, T. : Growth rate, seasonal, synoptic, diurnal variations and budget of methane in lower atmosphere, J. Meteorol. Soc. Jpn., 87, 635-663, 2009.

Patra, P. K., Houweling, S., Krol, M., Bousquet, P., Belikov, D., Bergmann, D., Bian, H., Cameron-Smith, P., Chipperfield, M. P., Corbin, K., Fortems-Cheiney, A., Fraser, A., Gloor, E., Hess, P., Ito, A., Kawa, S. R., Law, R. M., Loh, Z., Maksyutov, S., Meng, L., Palmer, P. I., Prinn, R. G., Rigby, M., Saito, R., and Wilson, C.: TransCom model simulations of $\mathrm{CH}_{4}$ and related species: linking transport, surface flux and chemical loss with $\mathrm{CH}_{4}$ variability in the troposphere and lower stratosphere, Atmos. Chem. Phys., 11, 12813-12837, doi:10.5194/acp-11-12813-2011, 2011.

Pougatchev, N. S., Connor, B. J., and Rinsland, C. P.: Infrared measurements of the ozone vertical distribution above Kitt Peak, J. Geophys. Res., 100, 16689-16697, 1995.

Rothman, L. S., Barbe, A., Benner, D. C., Brown, L. R., CamyPeyret, C., Carleer, M. R., Chance, K., Clerbaux, C., Dana, V., Devi, V. M., Fayt, A., Flaud, J. M., Gamache, R. R., Goldman, A., Jacquemart, D., Jucks, K. W., Lafferty, W. J., Mandin, J. Y., Massie, S. T., Nemtchinov, V., Newnham, D. A., Perrin, A., Rinsland, C. P., Schroeder, J., Smith, K. M., Smith, M. A. H., Tang, K., Toth, R. A., Vander Auwera, J., Varanasi, P., and Yoshino, K.: The HITRAN molecular spectroscopic database: edition of 2000 including updates through 2001, J. Quant. Spectrosc. Radiat. Transfer, 82, 5-44, 2003.

Rothman, L. S., Jacquemart, D., Barbe, A., Benner, D. C., Birk, M., Brown, L. R., Carleer, M. R., Chackerian, C., Chance, K., Coudert, L. H., Dana, V., Devi, V. M., Flaud, J. M., Gamache, R. R., Goldman, A., Hartmann, J. M., Jucks, K. W., Maki, A. G., Mandin, J. Y., Massie, S. T., Orphal, J., Perrin, A., Rinsland, C. P., Smith, M. A. H., Tennyson, J., Tolchenov, R. N., Toth, R. A., Vander Auwera, J., Varanasi, P., and Wagner, G.: The HITRAN 2004 molecular spectroscopic database, J. Quant. Spectrosc. Rad. Trans., 96, 139-204, doi:10.1016/j.jqsrt.2004.10.008, 2005.

Rothman, L. S., Gordon, I. E., Barbe, A., Benner, D. C., Bernath, P. F., Birk, M., Boudon, V., Brown, L. R., Campargue, A., Champion, J., Chance, K., Coudert, L. H., Dana, V., Devi, V. M., Fally, S., Flaud, J.M., Gamache, R. R., Goldman, A., Jacquemart, D., Kleiner, I., Lacome, N., Lafferty, W. J., Mandin, J., Massie, S. T., Mikhailenko, S. N., Miller, C. E., Moazzen-Ahmadi, N., Naumenko, O. V., Nikitin, A. V., Orphal, J., Perevalov, V. I., Perrin, A., Predoi-Cross, A., Rinsland, C. P., Rotger, M., Šimečková, M., Smith, M. A. H., Sung, K., Tashkun, S. A., Tennyson, J., Toth, R. A., Vandaele, A. C., and Vander Auwera, J.: The HITRAN 2008 molecular spectroscopic database, J. Quant. Spectrosc. Radiat. Transfer, 110, 533-572, 2009.

Saad, K. M., Wunch, D., Toon, G. C., Bernath, P., Boone, C., Connor, B., Deutscher, N. M., Griffith, D. W. T., Kivi, R., Notholt,
J., Roehl, C., Schneider, M., Sherlock, V., and Wennberg, P. O.: Derivation of tropospheric methane from TCCON $\mathrm{CH}_{4}$ and HF total column observations, Atmos. Meas. Tech., 7, 2907-2918, doi:10.5194/amt-7-2907-2014, 2014.

Saito, R., Patra, P. K., Deutscher, N., Wunch, D., Ishijima, K., Sherlock, V., Blumenstock, T., Dohe, S., Griffith, D., Hase, F., Heikkinen, P., Kyrö, E., Macatangay, R., Mendonca, J., Messerschmidt, J., Morino, I., Notholt, J., Rettinger, M., Strong, K., Sussmann, R., and Warneke, T.: Technical Note: Latitude-time variations of atmospheric column-average dry air mole fractions of $\mathrm{CO}_{2}, \mathrm{CH}_{4}$ and $\mathrm{N}_{2} \mathrm{O}$, Atmos. Chem. Phys., 12, 7767-7777, doi:10.5194/acp12-7767-2012, 2012.

Sapart, S. J., Monteil, G., Prokopiou, M., van de Wal, R. S. W., Kaplan, J. O., Sperlich, P., Krumhardt, K. M., van der Veen, C., Houweling, S., Krol, M. C., Blunier, T., Sowers, T., Martinerie, P., Witrant, E., Dahl-Jensen, D., and Röckmann, T.: Natural and anthropogenic variations in methane sources during the past two millennia, Nature, 490, 85-88, doi:10.1038/nature11461, 2012.

Schneising, O., Bergamaschi, P., Bovensmann, H., Buchwitz, M., Burrows, J. P., Deutscher, N. M., Griffith, D. W. T., Heymann, J., Macatangay, R., Messerschmidt, J., Notholt, J., Rettinger, M., Reuter, M., Sussmann, R., Velazco, V. A., Warneke, T., Wennberg, P. O., and Wunch, D.: Atmospheric greenhouse gases retrieved from SCIAMACHY: comparison to ground-based FTS measurements and model results, Atmos. Chem. Phys., 12, 1527-1540, doi:10.5194/acp-12-1527-2012, 2012.

Sepúlveda, E., Schneider, M., Hase, F., García, O. E., GomezPelaez, A., Dohe, S., Blumenstock, T., and Guerra, J. C.: Longterm validation of tropospheric column-averaged $\mathrm{CH}_{4}$ mole fractions obtained by mid-infrared ground-based FTIR spectrometry, Atmos. Meas. Tech., 5, 1425-1441, doi:10.5194/amt-5-14252012, 2012.

Sepúlveda, E., Schneider, M., Hase, F., Barthlott, S., Dubravica, D., García, O. E., Gomez-Pelaez, A., González, Y., Guerra, J. C., Gisi, M., Kohlhepp, R., Dohe, S., Blumenstock, T., Strong, K., Weaver, D., Palm, M., Sadeghi, A., Deutscher, N. M., Warneke, T., Notholt, J., Jones, N., Griffith, D. W. T., Smale, D., Brailsford, G. W., Robinson, J., Meinhardt, F., Steinbacher, M., Aalto, T., and Worthy, D.: Tropospheric $\mathrm{CH}_{4}$ signals as observed by NDACC FTIR at globally distributed sites and comparison to GAW surface in situ measurements, Atmos. Meas. Tech., 7, 2337-2360, doi:10.5194/amt-7-2337-2014, 2014.

Sinnhuber, B.-M., Stiller, G., Ruhnke, R., von Clarmann, T., Kellmann, S., and Aschmann, J.:, Arctic winter 2010/2011 at the brink of an ozone hole, Geophys. Res. Lett., 38, L24814, doi:10.1029/2011GL049784, 2011.

Sprenger, M. and Wernli, H.: A northern hemispheric climatology of crosstropopause exchange for the ERA15 time period (19791993), J. Geophys. Res., 108, 8521, doi:10.1029/2002JD002636, 2003.

Stocker, T., Qin, D., Plattner, G. K., Tignor, M., Allen, S. K., Boschung, J., Nauels, A., Xia, Y., Bex, V., and Midgley, P. M (Eds.): Summary for Policymakers, Climate Change 2013: The Physical Science Basis. Contribution of Working Group I to the Fifth Assessment Report of the Intergovernmental Panel on Climate Change, Cambridge University Press, Cambridge, United Kingdom and New York, NY, USA, 2013.

Stohl, A. and Trickl, T.: A textbook example of long-range transport: Simultaneous observation of ozone maxima of stratospheric 
and North American origin in the free troposphere over Europe, J. Geophys. Res., 104, 30445-30462, 1999.

Stohl, A., Spichtinger-Rakowsky, N., Bonasoni, P., Feldmann, H., Memmesheimer, M., Scheel, H. E., Trickl, T., Hübener, S. H., Ringer, W., and Mandl, M.: The influence of stratospheric intrusions on alpine ozone concentrations, Atmos. Environ., 34, 1323-1354, 2000.

Stohl, A., Bonasoni, P., Cristofanelli, P., Collins, W., Feichter, J., Frank, A., Forster, C., Gerasopoulos, E., Gäggeler, H., James, P., Kentarchos, T., Kromp-Kolb, H., Krüger, B., Land, C., Meloen, J., Papayannis, A., Priller, A., Seibert, P., Sprenger, M., Roelofs, G. J., Scheel, H. E., Schnabel, C., Siegmund, P., Tobler, L., Trickl, T., Wernli, H., Wirth, V., Zanis, P., and Zerefos, C.: Stratosphere-troposphere exchange: a review, and what we have learned from STACCATO, J. Geophys. Res., 108, 8516, doi:10.1029/2002JD002490, 2003.

Sussmann, R., Stremme, W., Buchwitz, M., and de Beek, R.: Validation of ENVISAT/SCIAMACHY columnar methane by solar FTIR spectrometry at the Ground-Truthing Station Zugspitze, Atmos. Chem. Phys., 5, 2419-2429, doi:10.5194/acp-5-24192005, 2005.

Sussmann, R., Borsdorff, T., Rettinger, M., Camy-Peyret, C., Demoulin, P., Duchatelet, P., Mahieu, E., and Servais, C.: Technical Note: Harmonized retrieval of column-integrated atmospheric water vapor from the FTIR network - first examples for longterm records and station trends, Atmos. Chem. Phys., 9, 89878999, doi:10.5194/acp-9-8987-2009, 2009.

Sussmann, R., Forster, F., Rettinger, M., and Jones, N.: Strategy for high-accuracy-and-precision retrieval of atmospheric methane from the mid-infrared FTIR network, Atmos. Meas. Tech., 4, 1943-1964, doi:10.5194/amt-4-1943-2011, 2011.

Sussmann, R., Forster, F., Rettinger, M., and Bousquet, P.: Renewed methane increase for five years (2007-2011) observed by solar FTIR spectrometry, Atmos. Chem. Phys., 12, 4885-4891, doi:10.5194/acp-12-4885-2012, 2012.

Sussmann, R., Ostler, A., Forster, F., Rettinger, M., Deutscher, N. M., Griffith, D. W. T., Hannigan, J. W., Jones, N., and Patra, P. K.: First intercalibration of column-averaged methane from the Total Carbon Column Observing Network and the Network for the Detection of Atmospheric Composition Change, Atmos. Meas. Tech., 6, 397-418, doi:10.5194/amt-6-397-2013, 2013.

Toon, G. C., Farmer, C. B., Schaper, P.W., Lowes, L. L., Norton, R. H., Schoeberl, M. R., Lait, L. R., and Newman, P. A.: Evidence for subsidence in the 1989 Polar winter stratosphere from airborne infrared composition measurements, J. Geophys. Res., 97, 7963-7970, 1992.

Trickl, T., Cooper, O. C., Eisele, H., James, P., Mücke, R., and Stohl, A.: Intercontinental transport and its influence on the ozone concentrations over central Europe: Three case studies, J. Geophys. Res., 108, 8530, doi:10.1029/2002JD002735, 2003.

Trickl, T., Feldmann, H., Kanter, H.-J., Scheel, H.-E., Sprenger, M., Stohl, A., and Wernli, H.: Forecasted deep stratospheric intrusions over Central Europe: case studies and climatologies, Atmos. Chem. Phys., 10, 499-524, doi:10.5194/acp-10-499-2010, 2010.

Trickl, T., Vogelmann, H., Giehl, H., Scheel, H.-E., Sprenger, M., and Stohl, A.: How stratospheric are deep stratospheric intrusions?, Atmos. Chem. Phys., 14, 9941-9961, doi:10.5194/acp14-9941-2014, 2014.
Wang, Z., Deutscher, N. M., Warneke, T., Notholt, J., Dils, B., Griffith, D. W. T., Schmidt, M., Ramonet, M., and Gerbig, C.: Retrieval of tropospheric column-averaged $\mathrm{CH}_{4}$ mole fraction by solar absorption FTIR-spectrometry using $\mathrm{N}_{2} \mathrm{O}$ as a proxy, Atmos. Meas. Tech., 7, 3295-3305, doi:10.5194/amt-7-3295-2014, 2014.

Washenfelder, R. A., Wennberg, P. O., and Toon, G. C.: Tropospheric methane retrieved from ground-based near-IR solar absorption spectra, Geophys. Res. Lett., 30, 2226, doi:10.1029/2003GL017969, 2003.

Wernli, H. and Davies, H. C.: A Lagrangian-based analysis of extratropical cyclones, I, The method and some applications, Q. J. R. Meteorol. Soc., 123, 467-489, 1997.

Wofsy, S. C. and the HIPPO Science Team and Cooperating Modellers and Satellite Teams: TS6 HIAPER Pole-to-Pole Observations (HIPPO): fine-grained, global-scale measurements of climatically important atmospheric gases and aerosols, Philos. T. Roy. Soc. A, 369, 2073-2086, doi:10.1098/rsta.2010.0313, 2011.

Wunch, D., Toon, G. C., Wennberg, P. O., Wofsy, S. C., Stephens, B. B., Fischer, M. L., Uchino, O., Abshire, J. B., Bernath, P., Biraud, S. C., Blavier, J.-F. L., Boone, C., Bowman, K. P., Browell, E. V., Campos, T., Connor, B. J., Daube, B. C., Deutscher, N. M., Diao, M., Elkins, J. W., Gerbig, C., Gottlieb, E., Griffith, D. W. T., Hurst, D. F., Jiménez, R., Keppel-Aleks, G., Kort, E. A., Macatangay, R., Machida, T., Matsueda, H., Moore, F., Morino, I., Park, S., Robinson, J., Roehl, C. M., Sawa, Y., Sherlock, V., Sweeney, C., Tanaka, T., and Zondlo, M. A.: Calibration of the Total Carbon Column Observing Network using aircraft profile data, Atmos. Meas. Tech., 3, 1351-1362, doi:10.5194/amt3-1351-2010, 2010.

Wunch, D., Toon, G. C., Blavier, J.-F. L., Washenfelder, R. A., Notholt, J., Connor, B. J., Griffith, D. W. T., Sherlock, V., and Wennberg, P. O.: The Total Carbon Column Observing Network, Phil. Trans. R. Soc. A, 369, 2087-2112, doi:10.1098/rsta.2010.0240, 2011a.

Wunch, D., Wennberg, P. O., Toon, G. C., Connor, B. J., Fisher, B., Osterman, G. B., Frankenberg, C., Mandrake, L., O’Dell, C., Ahonen, P., Biraud, S. C., Castano, R., Cressie, N., Crisp, D., Deutscher, N. M., Eldering, A., Fisher, M. L., Griffith, D. W. T., Gunson, M., Heikkinen, P., Keppel-Aleks, G., Kyrö, E., Lindenmaier, R., Macatangay, R., Mendonca, J., Messerschmidt, J., Miller, C. E., Morino, I., Notholt, J., Oyafuso, F. A., Rettinger, M., Robinson, J., Roehl, C. M., Salawitch, R. J., Sherlock, V., Strong, K., Sussmann, R., Tanaka, T., Thompson, D. R., Uchino, O., Warneke, T., and Wofsy, S. C.: A method for evaluating bias in global measurements of $\mathrm{CO}_{2}$ total columns from space, Atmos. Chem. Phys., 11, 12317-12337, doi:10.5194/acp11-12317-2011, 2011b.

Xiong, X., Barnet, C., Maddy, E., Wofsy, S. C., Chen, L., Karion, A., and Sweeney, C.: Detection of methane depletion associated with stratospheric intrusion by atmospheric infrared sounder (AIRS), Geophys. Res. Lett., 40, 2455-2459, doi:10.1002/grl.50476, 2013.

Yoshida, Y., Ota, Y., Eguchi, N., Kikuchi, N., Nobuta, K., Tran, H., Morino, I., and Yokota, T.: Retrieval algorithm for $\mathrm{CO}_{2}$ and $\mathrm{CH}_{4}$ column abundances from short-wavelength infrared spectral observations by the Greenhouse gases observing satellite, Atmos. Meas. Tech., 4, 717-734, doi:10.5194/amt-4-717-2011, 2011. 